\title{
Uncertainty and Spatial Correlation of Earthquake Ground Motion in Taiwan
}

\author{
Vladimir Sokolov ${ }^{1, *}$, Friedemann Wenzel $^{1}$, Wen-Yu Jean ${ }^{2}$, and Kuo-Liang Wen ${ }^{2,3}$ \\ ${ }^{1}$ Geophysical Institute, Karlsruhe Institute of Technology (KIT), Karlsruhe, Germany \\ ${ }^{2}$ National Center for Research on Earthquake Engineering, Taipei, Taiwan, ROC \\ ${ }^{3}$ Institute of Geophysics, National Central University, Jhongli, Taiwan, ROC
}

Received 16 March 2010, accepted 3 May 2010

\begin{abstract}
In this work we analyzed characteristics of aleatory variability with regard to intra-event and inter-event components in the prediction of peak ground acceleration in Taiwan and the spatial (site-to-site) correlation of ground motion residuals. The characteristics are very important for an assessment of seismic hazard and loss for regionally located building assets (portfolio) and spatially distributed systems (lifelines) and ShakeMap generation. The strong-motion database collected by the TSMIP network in Taiwan, which includes about 4650 records from 66 shallow earthquakes $\left(\mathrm{M}_{\mathrm{L}}>4.5\right.$, focal depth $\left.<30 \mathrm{~km}\right)$ occurred in 1993 - 2004, was used for this purpose. The results of the analysis show that the ground motion correlation structure is highly dependent on local geology and on peculiarities of the propagation path (azimuth-dependent attenuation). Thus, a single generalized spatial correlation model may not be adequate for all of Taiwan territory or similar large areas.
\end{abstract}

Key words: Ground motion uncertainty, Spatial correlation, Taiwan

Citation: Sokolov, V., F. Wenzel, W. Y. Jean, and K. L. Wen, 2010: Uncertainty and spatial correlation of earthquake ground motion in Taiwan. Terr. Atmos. Ocean. Sci., 21, 905-921, doi: 10.3319/TAO.2010.05.03.01(T)

\section{INTRODUCTION}

A key element in estimation of seismic hazard and seismic loss is consideration of uncertainties, which can be classified as epistemic and aleatory. The epistemic uncertainty reflects the incomplete knowledge of the nature of all inputs to the assessment and variability of interpretation of available data. For ground-motion models, epistemic uncertainty results from a limited amount of observed data. Epistemic uncertainty can be incorporated into seismic hazard assessment using a logic tree method (e.g., Reiter 1990; Bommer et al. 2005). The alternative models are weighted in the analysis according to their probability of being correct.

Aleatory uncertainty, which is related to the inevitable unpredictability of nature of ground motion parameters, is mainly quantified in SHA through the use of the standard deviation of the scatter of the data about the ground motion prediction equations. In other words, the aleatory uncertainty describes the disagreement between observations and predictive models which is due to the absence of a physical explanation or due to the variables that are not included in

\footnotetext{
* Corresponding author

E-mail: vladimir.sokolov@kit.edu
}

the predictive equations. Thus, the aleatory component of uncertainty may reflect also epistemic modeling uncertainty regarding the factors controlling the ground motion component that have not been included in ground motion models (e.g., Strasser et al. 2009).

The total aleatory variability is separated into several independent components (Brillinger and Preisler 1984, 1985; Abrahamson and Youngs 1992; Joyner and Boore 1993). The components represent (1) the earthquake-to-earthquake (inter-event) variability; (2) the site-to-site (intra-event) variability; and (3) variability remaining after accounting for the inter-event and the intra-event variability. The last two components may be joined into a single one.

The inter-event variability emphasizes that earthquake ground motion at different sites caused by the same earthquake must have something in common; the component of variability depends on variations of earthquake source characteristics. The intra-event variability considers the proposition that earthquake ground motion for a given event at different sites must vary to some extent. The variability is determined mostly by peculiarities of propagation path and local site conditions. Tsai and Liu (2006) separated the 
intra-event variability into the path-to-path and the site-tosite components. The inter-event correlation of earthquake ground motion, or similarity of ground motion variability during different earthquakes at the same site, is determined by a relation between the components of variability. At the same time, two close sites may exhibit a correlation of ground motion during an earthquake due to commonality of wave paths with regard to the site separation distance (the inter-event site-to-site correlation).

The ground motion correlation should be taken into account when estimating ground motion parameters along a wide area, for example, in an assessment of a seismic hazard and loss for regionally located building assets (portfolio) and spatially distributed systems (lifelines), ShakeMap generation, etc. The rigorous methodology described by Rhoades and McVerry (2001), Wesson and Perkins (2001), and McVerry et al. (2004) for assessing the joint hazard for spatially distributed sites requires consideration of the interevent and the intra-event components of uncertainty. When estimating the earthquake hazard in a probabilistic manner, the ratio between joint probabilities and the probabilities at individual sites can vary depending on (1) the inter-event correlation or ratio of inter-event and total components of variability, and on (2) whether or not the hazard is dominated by one source or many sources.

Knowledge of the distribution of loss about the mean (e.g., the variance or standard deviation) is very important for decision making and subsequent mitigation activities. For example, primary insurers are concerned with the central part of the distribution (mean and median values), while re-insurers deal mostly with the tail of the distribution. The probability distribution function for the loss to a portfolio (e.g., fractiles and standard deviation) depends upon, not only a damage correlation (the type and quality of vulnerable elements), but a ground motion correlation as well (e.g., Rhoades and McVerry 2001; Wesson and Perkins 2001; Lee et al. 2004; McVerry et al. 2004; Bommer and Crowley 2006; Molas et al. 2006; Park et al. 2007; Crowley et al. 2008; Goda and Hong 2008a; Sokolov and Wenzel 2009).

Several modern ground motion attenuation equations (e.g., Next Generation Attenuation models, NGA) incorporate the inter-event correlation, because the equations include specification of the inter-event and the intra-event components of variability (e.g., Boore et al. 1997; Tsai and Liu 2006; Abrahamson et al. 2008, see also Douglas 2003, 2006). In the NGA model created by Abrahamson and Silva (2008) both inter-event and intra-event components of variation depend on earthquake magnitude, soil properties (average shear wave velocity to a depth of $30 \mathrm{~m}$, Vs30), and level of ground motion amplitude.

The site-to-site correlation should be analyzed for a given area, empirically. A dense observation of records from numerous earthquakes is necessary for modeling the siteto-site correlation structure; therefore the correlation has not been extensively investigated. Boore et al. (2003), Hok and Wald (2003), and Lin et al. (2006) considered one or few particular earthquakes in California; Wang and Takada (2005) analyzed separately 5 earthquakes in Japan and the Chi-Chi earthquake in Taiwan. Kawakami and Mogi (2003) used records from many earthquakes in Japan (the Chiba array $30 \mathrm{~km}$ east of Tokyo; SIGNAL array in Tokyo), and Taiwan (SMART-1 array). Evans and Baker (2006) used the NGA database (Power et al. 2008) that is primarily based on the Californian data and a few earthquakes in Taiwan (the Chi-Chi earthquake and large aftershocks). Goda and Hong (2008b) and Jayaram and Baker (2009) considered the ChiChi earthquake and some Californian earthquakes and Hong et al (2009) analyzed only Californian data. Recently Goda and Atkinson (2009) used a large database collected in Japan (the records from the K_NET and KiK-net strong-motion networks) to study spatial correlation for peak ground acceleration and pseudo-spectral acceleration at different periods from 0.1 to $5.0 \mathrm{sec}$. The results reported by these research efforts reveal different rates of decay of correlation with separation distance. It has been shown that the difference is related to the frequency content of ground motion (e.g., Baker and Jayaram 2008; Goda and Hong 2008a). On the other hand, the difference may be caused by regional peculiarities (Goda and Atkinson 2009).

In fact, the site-to-site correlation depends on ground conditions of the sites and it will decrease for sites that do not share the same geology. Baker and Jayaram (2008) and Jayaram and Baker (2009) mentioned the influence on site characteristics (Vs30) on the spatial correlation for shortperiod ground motion parameters. However, no systematic research on quantifying the dependence has been performed so far.

In this work we analyzed the database accumulated since 1994 in Taiwan in order to estimate components of uncertainty and characteristics of ground motion correlation for peak ground acceleration. The whole database is considered to estimate the general characteristics of correlation and a region-dependent analysis has been performed.

\section{GROUND MOTION CORRELATION AND ITS AP- PLICATION TO GROUND MOTION MODELING}

The ground motion parameter $Y$ at $n$ locations during $m$ earthquakes is represented by

$$
\begin{aligned}
\log Y_{i, j} & =f\left(e_{i}, p_{i, j}, s_{i, j}\right)+\eta_{i}+\varepsilon_{i, j} \\
{[i} & =1,2, \ldots, m ; \quad j=1,2, \ldots, n]
\end{aligned}
$$

where $e_{i}$ denotes variables that are properties of the earthquake source; $p_{i, j}$ are the properties of propagation path; $s_{i, j}$ are the properties of site location $j$ during earthquake $i$; and, $f$ is a suitable function, which describes the depen- 
dence of median value of ground-motion parameter $\log \bar{Y}_{i, j}$ on magnitude, distance, local site conditions, etc, i.e., $\log \bar{Y}_{i, j}=f\left(e_{i}, p_{i, j}, s_{i, j}\right)$. The random variables $\eta_{i}$ and $\varepsilon_{i, j}$ represent the inter-event and intra-event components of variability (independent and normally distributed with variances $\sigma_{\eta}^{2}$ and $\sigma_{\varepsilon}^{2}$ ). The value of $\eta_{i}$ is common to all sites during a particular earthquake $i$, and the value of $\varepsilon_{i, j}$ depends on the site. Assuming independence of the two random terms, the total aleatory variance $\sigma_{T}^{2}$ is given by $\sigma_{T}^{2}=\sigma_{\eta}^{2}+\sigma_{\varepsilon}^{2}$ (e.g., Brillinger and Preisler 1984, 1985; Abrahamson and Youngs 1992; Joyner and Boore 1993; Boore et al. 1997). Note that if the pseudospectral acceleration (PSA) is considered, the variances $\sigma_{\eta}^{2}$ and $\sigma_{\varepsilon}^{2}$ are the functions of the natural vibration period $T$ (see Goda and Hong 2008a).

Let us consider a ground motion parameter and correspondent error random variables (normally distributed with zero mean and standard deviations $\sigma_{\eta}$ and $\sigma_{\varepsilon}$ ) at two sites $z_{1}=\eta+\varepsilon_{z 1}$ and $z_{2}=\eta+\varepsilon_{z 2}$. The joint probability density function follows bivariate normal distribution with zero means and standard deviation $\sigma_{T}$. The correlation structure is described as follows. First, the inter-event residual is the same for the sites for a single earthquake; therefore the interevent correlation coefficient (Wesson and Perkins 2001) is

$$
\rho_{\eta}=\sigma_{\eta}^{2} /\left(\sigma_{\eta}^{2}+\sigma_{\varepsilon}^{2}\right)=\sigma_{\eta}^{2} / \sigma_{T}^{2}
$$

Two close sites may exhibit a correlation of ground motion during an earthquake due to commonality of wave paths (intra-event site-to-site correlation), which depends on the site separation distance. For earthquake $i$ and site $j$ the total correlation is (Park et al. 2007)

$$
\rho_{T}(\Delta)=\frac{\sigma_{\eta}^{2}+\rho_{\varepsilon}(\Delta) \sigma_{\varepsilon}^{2}}{\sigma_{T}^{2}}=\rho_{\eta}+\rho_{\varepsilon}(\Delta)\left(\frac{\sigma_{\varepsilon}^{2}}{\sigma_{T}^{2}}\right)
$$

where $\rho_{\varepsilon}(\Delta)=\rho_{\varepsilon_{i, j, 1} ; \varepsilon_{i, j, 2}}(\Delta)$ is the empirical correlation coefficient calculated for intra-event $\varepsilon_{i, j}$ values separated by a distance $\Delta$. Thus, the dependence structure among the $n$ total error random variables is described by correlation matrix $\Sigma$.

$\Sigma=\left(\begin{array}{cccc}1 & \rho_{12} & \cdots & \rho_{1 n} \\ \rho_{21} & 1 & \cdots & \rho_{2 n} \\ \vdots & \vdots & \vdots & \vdots \\ \rho_{n 1} & \rho_{n 2} & \cdots & 1\end{array}\right)$

where $\rho_{i j}$ is the empirical total correlation coefficient [Eq. (3)] calculated for the sites separated by a distance $\Delta$.

The correlation may be estimated as follows. Let $Z(x)$ denote the total residuals between the log of observations at a site $\mathrm{x}$ and that of the value predicted from the mean attenuation relationship, i.e., $Z(x)=\log Y_{i j}-\log \bar{Y}_{i j}$. It is assumed that $Z(x)$ is a homogeneous $2 \mathrm{D}$ stochastic field, however the homogeneity should be examined for every considered case (e.g., Wang and Takada 2005). The covariance function of the values $Z\left(x_{1}\right)$ and $Z\left(x_{2}\right)$ is described as

$$
\begin{aligned}
\operatorname{COV}\left[Z\left(x_{1}\right), Z\left(x_{2}\right)\right] & =\operatorname{COV}(\Delta) \\
& =E\left\{\left[Z\left(x_{1}\right)-\mu_{z}\right]\left[Z\left(x_{2}\right)-\mu_{z}\right]\right\}
\end{aligned}
$$

where $E[\cdot]$ denotes an expectation; $\Delta$ is a separation distance between the locations $x_{1}$ and $x_{2}$; and $\mu_{Z}$ is the mean value of $Z(x)$. Correlation function is obtained by normalizing covariance function with the variation $\sigma_{z}^{2}$

$\rho\left[Z\left(x_{1}\right), Z\left(x_{2}\right)\right]=\rho(\Delta)=\frac{\operatorname{COV}(\Delta)}{\sigma_{Z}^{2}}$

A discrete expression of the equations follows

$\mu_{z}=\frac{1}{N_{\text {all }}} \sum_{i=1}^{N_{\text {all }}} Z\left(x_{i}\right)$

$\operatorname{COV}(\Delta)=\frac{1}{N(\Delta)} \sum_{i=1}^{N(\Delta)}\left[Z\left(x_{i}\right)-\mu_{z}\right]\left[Z\left(x_{i}+\Delta\right)-\mu_{z}\right]$

where $N_{\text {all }}$ is the total number of observation sites; $N(\Delta)$ is the number of pairs of sites separated by $\Delta$. The function $\rho_{\varepsilon}(\Delta)$ may be represented by an exponential decay function (e.g., Boore et al. 2003; Wang and Takada 2005; Goda and Hong 2008b)

$\rho_{\varepsilon}(\Delta)=\exp \left(a \Delta^{b}\right)$

where $a$ and $b$ are the region-dependent coefficients.

The uncertainty $Z(x)$ comprises the inter-event $\eta$ and the intra-event $\varepsilon$ uncertainty. The inter-event residual $\eta$ is a constant across all the sites during a given earthquake. Therefore, when using records from a single earthquake, estimation of the intra-event site-to-site correlation $\rho_{\varepsilon}(\Delta)$ does not require the knowledge of the inter-event residual for the earthquake. However, when the used database contains records from several earthquakes, application of Eqs. (5) - (7) would result in estimation of the total correlation $\rho_{T}(\Delta)$. On one hand, the total correlation and the intra-event site-to-site correlation are related [Eq. (3)] and one can be calculated from the other if the standard deviations $\sigma_{\eta}$ and $\sigma_{\varepsilon}$ are given. On the other hand, the interevent component for earthquake $i$ may be removed from residuals using estimations of $\hat{\eta}_{i}$ [Eq. (10) in Abrahamson and Youngs 1992] 


$$
\hat{\eta}_{i}=\frac{\sigma_{\eta}^{2} \sum_{j=1}^{n_{i}} Y_{i, j}-\bar{Y}_{i, j}}{n_{i} \sigma_{\eta}^{2}+\sigma_{\varepsilon}^{2}}
$$

\section{THE DATA}

The strong-motion database, which was used in this study, includes records obtained at TSMIP stations from 66 shallow earthquakes $\left(\mathrm{M}_{\mathrm{L}}>4.5\right.$, focal depth $<30 \mathrm{~km}$, more than 4650 records) and occurred between 1993 - 2004 (see Figs. 1a and 2).

The data were obtained during implementation of the Taiwan Strong Motion Instrumentation Program, which was conducted by the Seismological Observation Center of the Central Weather Bureau (CWB), Taiwan, ROC. More than 650 digital free-field strong motion instruments were installed within 7 arrays (Fig. 1b). Each station includes one strong motion instrument: a force-balanced three-component accelerometer. Most of the recorders (Geotech and Terra Tech instruments) have a 16-bit resolution and several instruments (Kinemetrics) have a 24-bit resolution. These instruments are capable of recording high-resolution ground motion within $\pm 2 \mathrm{~g}$ along with a pre-event and post-event memory cache. All stations have AC power, and when the power system is shut down by an earthquake or other problem, the internal DC power of the recording system can still operate for about 4 days.

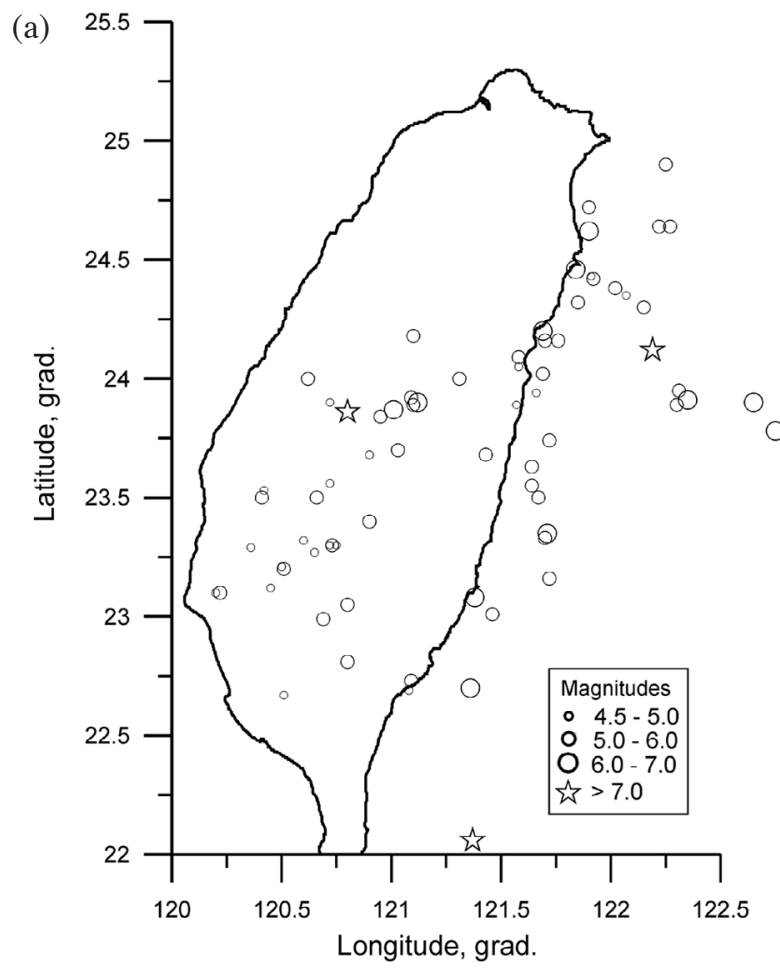

The following record selection criteria were used. First, the record should have clear P- and S-wave onsets. Second, only records, for which the signal-to-noise ratio exceeded 2 , were further processed. To check the ratio Fourier amplitude spectra of the strongest part of shaking (S-wave) and of the pre-event noise were calculated and compared (see Fig. 3).

The free-field strong-motion station sites in the Taiwan region were classified (Lee et al. 2001) using a scheme compatible with the 1994 and 1997 NEHRP provisions (BSSC 1998) which is based on the properties of the top 30 meters of the soil column, disregarding the characteristics of deeper geology. For Taiwan five site categories are defined on the basis of average shear wave velocity Vs30, namely: B - rock; C - very dense or stiff soil; D - stiff soil; E - soft soil; F - soils requiring special studies. The existing geological and geomorphologic data were analyzed, and the response spectral shape and the horizontal-to-vertical spectral ratio of response spectra data were used for the classification. It has been noted (Lee et al. 2001; Sokolov et al. 2004; Huang et al. 2005) that further studies on site classification should be carried out in the Taiwan region.

We used moment magnitude in our analysis. The earthquake catalogue collected by CWB shows local magnitudes. Therefore we considered several sources for determination of moment magnitude $\mathrm{M}_{\mathrm{W}}$ values, namely: Harvard seismic catalogue http://www.seismology.harvard.edu/; Institute of Earth Sciences, Academia Sinica http://tecws.earth.sinica.

(b)

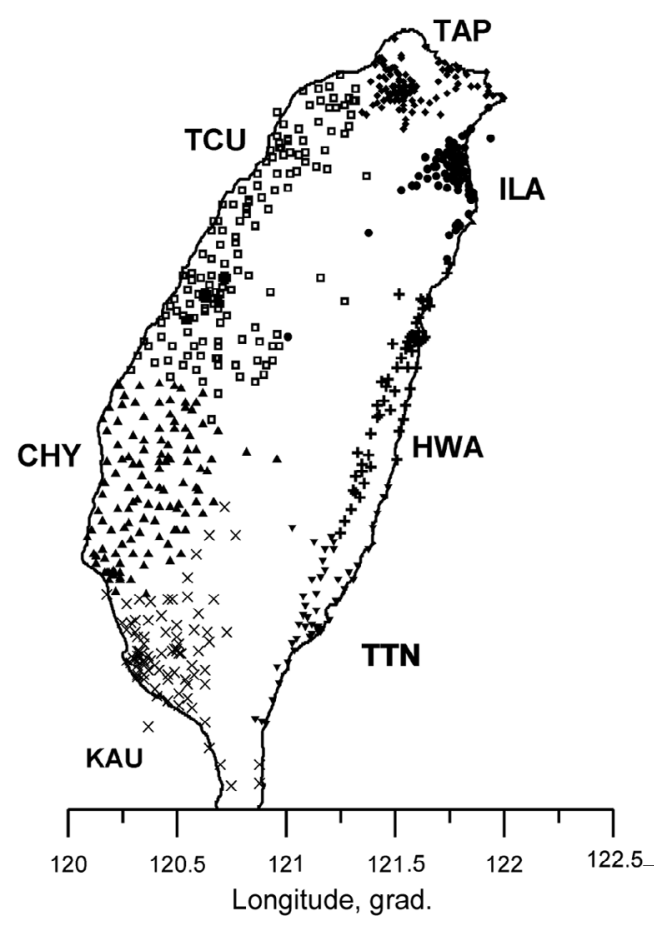

Fig. 1. The database used in this work. (a) Distribution of earthquake epicenters; (b) free-field strong-motion stations, arrays division. 
edu.tw (earthquake catalogue of Broadband Array in Taiwan for Seismology, BATS); and regional relationship between seismic moment and local magnitude (Lin and Lee 2008).

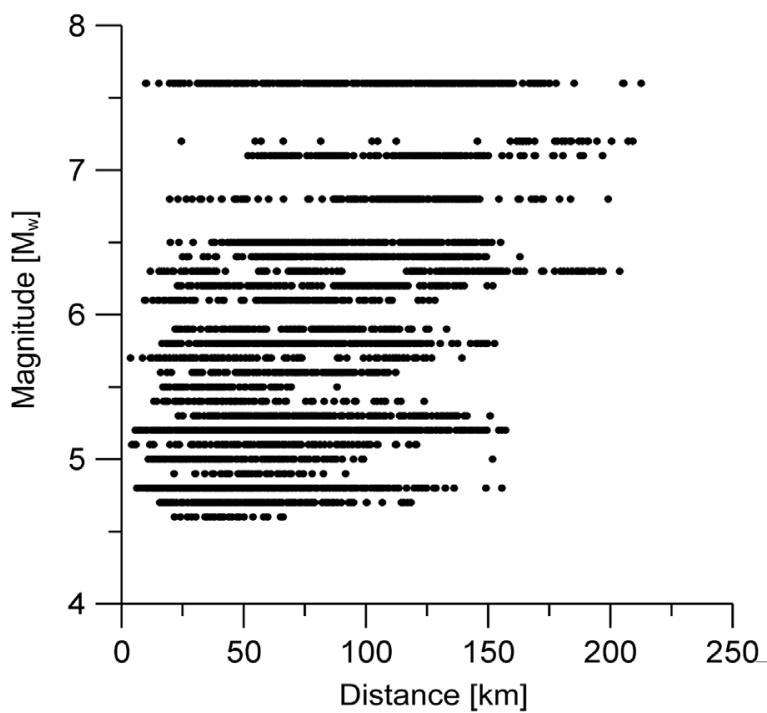

Fig. 2. Distribution of ground motion records versus magnitude and hypocentral distance.

\section{THE ANALYSIS}

\subsection{Ground Motion Models and Residuals}

The spatial correlation, in principle, depends on the chosen ground motion model, because the correlation describes behavior of residuals between observations and predictions and it is also strongly dependent on the partitioning of the variability into the inter-event and the intra-event components. Several empirical ground motion models were developed recently for Taiwan (e.g., Chang et al. 2001; Liu and Tsai 2005; Jean et al. 2006; Tsai et al. 2006; Lin and Lee 2008, see also Cheng et al. 2007 for the list of the models). However, only the model proposed by Tsai et al. (2006) considered the inter-event and the intra-event components of residuals. Table 1 shows characteristics of some ground-motion attenuation models (Chang et al. 2001; Liu and Tsai 2005; Tsai et al. 2006; and Cheng et al. 2007). A comparison of the predicted PGA values from the models is shown in Fig. 4.

When selecting a ground motion model for our study, we considered the following. The models developed by Tsai et al. (1987) were constructed using a very limited database. The model by Chang et al. (2001) does include records from earthquakes occurred after 1998, but it does not reflect the

(a)
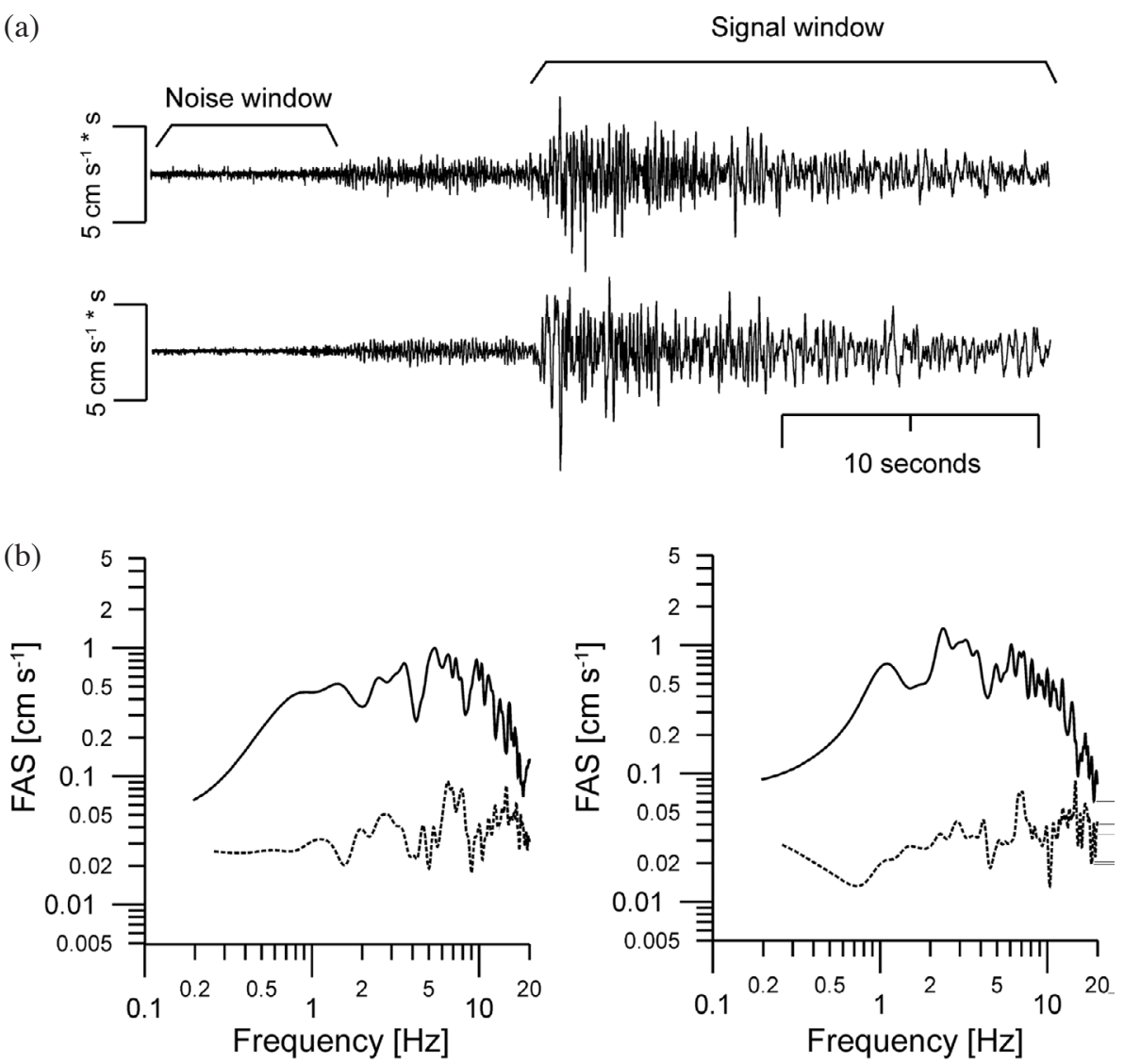

Fig. 3. Example of (a) horizontal components of the acceleration record and (b) Fourier amplitude spectra of the strongest part of shaking (solid lines) and the pre-event noise (dashed lines). Station CHY039, earthquake of 7 July 1999, $\mathbf{M}_{\mathrm{W}}$ 4.6, epicentral distance $65 \mathrm{~km}$. 
Table 1. Characteristics of ground-motion prediction models (horizontal components) recently developed for Taiwan.

\begin{tabular}{|c|c|c|c|}
\hline Reference/definition of the parameter & Magnitude definition & Distance definition & Standard Deviation $\left(\sigma_{T}, \sigma_{\eta}, \sigma_{\varepsilon}\right)$ \\
\hline Liu and Tsai 2005/arithmetical mean & Moment Magnitude & Hypocentral & $\sigma_{T}=0.719\left(\ln \mathrm{PGA}, \mathrm{cm} \mathrm{s}^{-2}\right)$ \\
\hline Chang et al. 2001/geometrical mean & Moment magnitude & Epicentral and Depth & $\sigma_{T}=0.6\left(\ln \mathrm{PGA}, \mathrm{cm} \mathrm{s}^{-2}\right)^{*}$ \\
\hline Cheng et al. 2007/geometric mean & Moment magnitude & Closest distance to fault rupture & $\sigma_{T}=0.55(\ln$ PGA, g) $* *$ \\
\hline \multirow[t]{3}{*}{ Tsai et al. 2006/geometric mean } & Local magnitude & Hypocentral & $\sigma_{T}=0.316\left(\log 10 \mathrm{PGA}, \mathrm{cm} \mathrm{s}^{-2}\right)$ \\
\hline & & & $\sigma_{T}=0.725\left(\ln \mathrm{PGA}, \mathrm{cm} \mathrm{s}^{-2}\right)$ \\
\hline & & & $\sigma_{\eta}=0.40 ; \sigma_{\varepsilon}=0.605^{* * *}$ \\
\hline
\end{tabular}

* The database contained records from earthquakes which occurred between 1994 - 1998.

** Soil conditions, hanging wall.

*** The intra-event component includes the site-to-site component and the residual error.
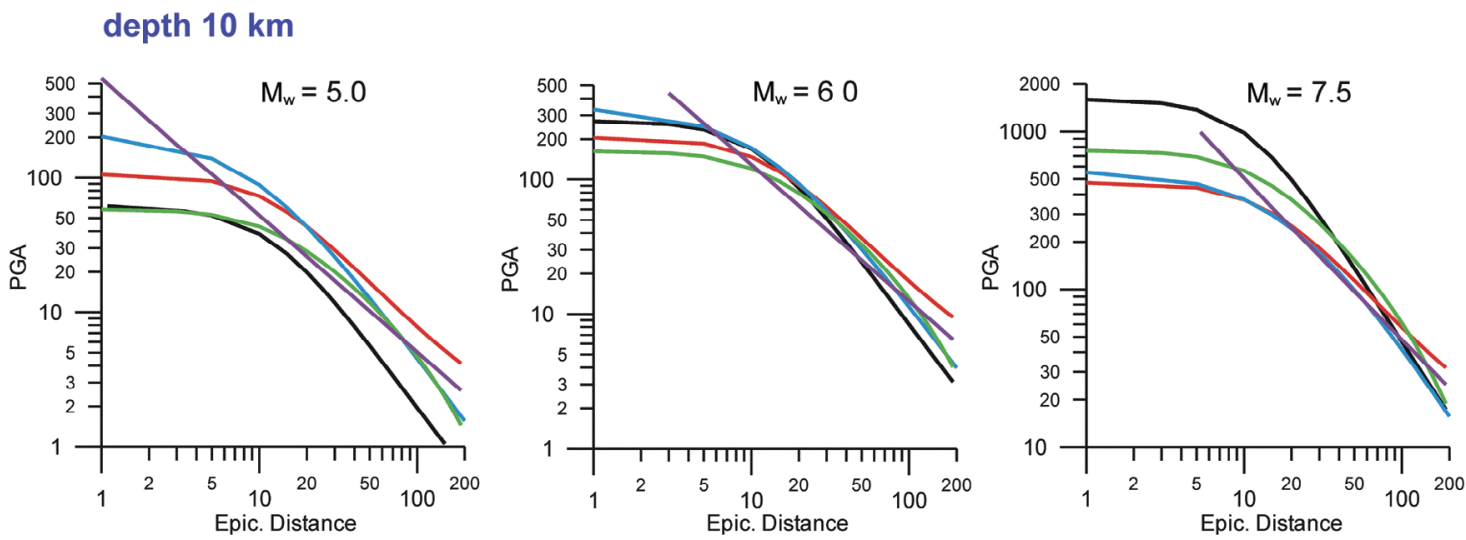

\section{depth $20 \mathrm{~km}$}
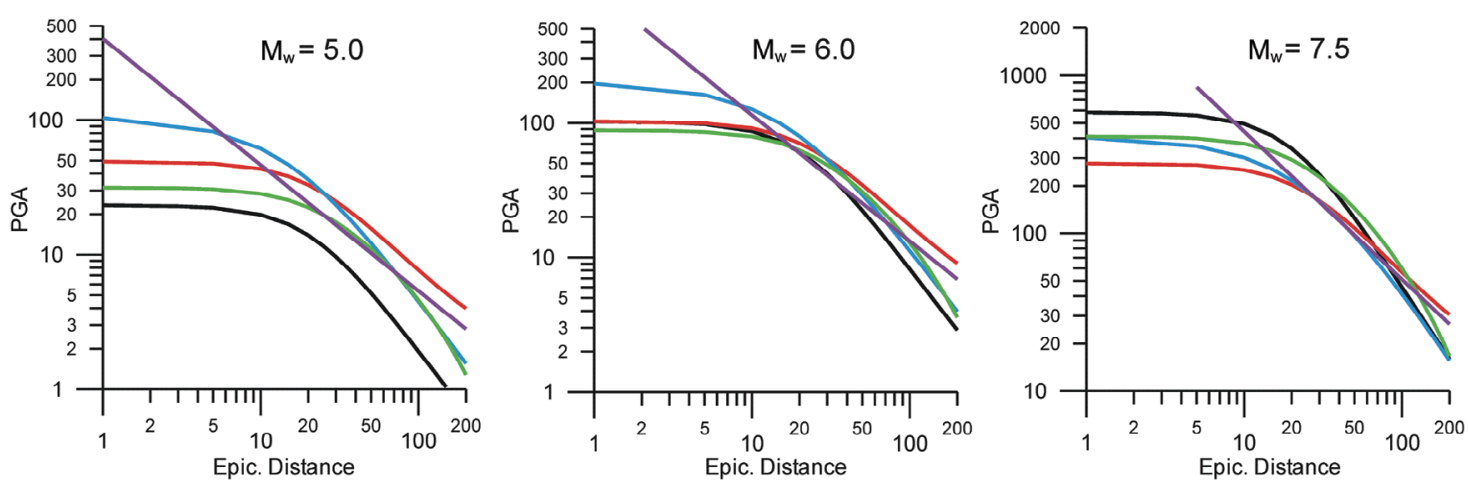

Fig. 4. Comparison of ground motion prediction models for Taiwan region. 1 - the model developed in this study [one step regression, Eq. (11a)]; 2 - Cheng et al. 2007; 3 - Liu and Tsai 2005; 4 - Chang et al. 2001; 5 - Tsai et al. 2006. The PGA values for the model developed by Cheng et al. (2007) are calculated as the averages from two estimations (the hanging wall and the foot wall variants). The model, which has been developed by Tsai et al. (2006) and which is based on local magnitude $\mathrm{M}_{\mathrm{L}}$, has been applied using $\mathrm{M}_{\mathrm{W}}-\mathrm{M}_{\mathrm{L}}$ transformation [Eq. (1) in Campbell et al. 2002].

saturation of ground motion parameters in a near-field zone. Cheng et al. (2007) provided several models for rock and soil sites and for hanging and foot walls of earthquake fault. Together with the necessity of using the closest distance to fault rupture plane, it is difficult to apply the models for numerous records and earthquakes. The model developed by Tsai et al. (2006) is based on local magnitude. Liu and Tsai (2005) considered arithmetic mean of horizontal compo- nents. Thus, for consistency with the general requirements for ground motion prediction models, we made an attempt to develop a new model that is based on moment magnitude values $\mathrm{M}_{\mathrm{W}}$ and geometric mean of maximum amplitudes at horizontal components. We seek the simplest reasonable functional form for the equation which, however, can describe the general features of the observed ground motions. We selected so-called Campbell's attenuation form 
(Campbell 1981), which includes a magnitude dependence of the transition from near-field to far-field attenuation. The similar form was used by Tsai et al. (2006) and Chang et al. (2007). Also we consider anelastic attenuation and the following equation has been accepted

$\ln G=a+b M_{W}+c \ln \left[R+d \exp \left(e M_{W}\right)\right]+p R+\eta+\varepsilon$

where $G$ is geometric mean of PGA of horizontal components, units of $\mathrm{g} ; R$ is hypocentral distance; $a, b, c, d, e$, and $p$ are coefficients of regression; $\eta$ and $\varepsilon$ are the inter-event and the intra-event components of random error, respectively. No attempt has been made to consider different site conditions in the generalized ground motion model. The influence of a local site condition was evaluated after estimation of the model. The anelastic attenuation (term $p R$ ) was also included into equations developed by Liu and Tsai (2005) and Tsai et al. (2006).

The base ground-motion prediction model has been determined using general multiple regression analysis and two-step regression analysis (Joyner and Boore 1981; Fukushima and Tanaka 1990; see also Chang et al. 2001; Kanno et al. 2006). The algorithm described by Abrahamson and Youngs (1992) was used to estimate the components of random error. The following models were derived thus.

\section{One-step generalized regression (1SR)}

$$
\begin{aligned}
& \ln G=-3.07+0.83 M_{W}-1.33 \ln \left[R+0.15 \exp \left(0.54 M_{W}\right)\right] \\
&+0.0023 R \\
& \sigma^{2}=0.44 ; \sigma=0.66 ; \eta^{2}=0.14 ; \eta=0.37 ; \varepsilon^{2}=0.30 ; \varepsilon=0.55
\end{aligned}
$$

Two-step regression (2SR)

$$
\begin{aligned}
\ln G= & -2.59+0.87 M_{W}-1.53 \ln \left[R+0.13 \exp \left(0.53 M_{W}\right)\right] \\
& +0.0029 R \\
\sigma^{2}= & 0.44 ; \sigma=0.67 ; \eta^{2}=0.15 ; \eta=0.39 ; \varepsilon^{2}=0.30 ; \varepsilon=0.55
\end{aligned}
$$

Figure 5a shows comparison of PGA values resulted from the both models. As expected (see Fukushima and Tanaka 1990), the 2SR-model shows the larger PGA at small distances and the smaller PGA at large distances than the 1SR model. Distribution of residuals between observed and predicted PGAs (i.e., $\ln P G A_{O B S}-\ln P G A_{P R E D}$ ) with respect to hypocentral distance is shown in Fig. 5b. Both models are characterized by the same values of standard deviation of residuals, while the bias of residuals (mean value) is the smallest for the 1SR model.

A comparison of the 1SR model [Eq. (11a)] with the ground motion models developed recently is shown in Fig. 4. Our model seems to provide an average assessment of PGA values, as compared with the other models, for small and intermediate magnitudes at distances less than 30 - $40 \mathrm{~km}$. For large magnitudes, the $1 \mathrm{SR}$ model results in the smaller PGA values at these distances than that estimated by the other considered models. Most near-field data for events of large magnitudes (epicentral distance less than 30 $40 \mathrm{~km})$ were obtained during the Chi-Chi $\left(\mathrm{M}_{\mathrm{W}} 7.6\right)$ earthquake. The analyses of the peak ground motions (e.g., EERI 2001; Tsai and Huang 2000; Boore 2001) showed that the overall level of the observed horizontal PGAs from the earthquake are about $50 \%$ below the median PGA based on commonly used attenuation in California for $\mathrm{M}_{\mathrm{W}}$ 7.6. The (a)

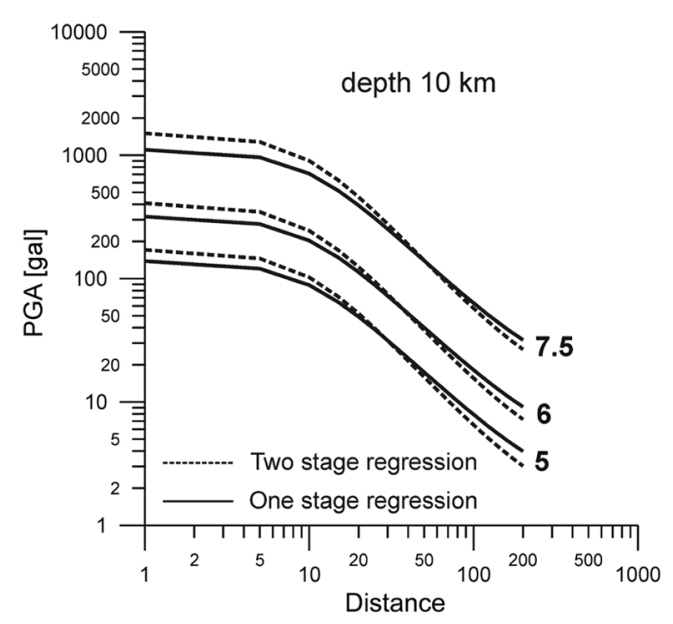

(b)
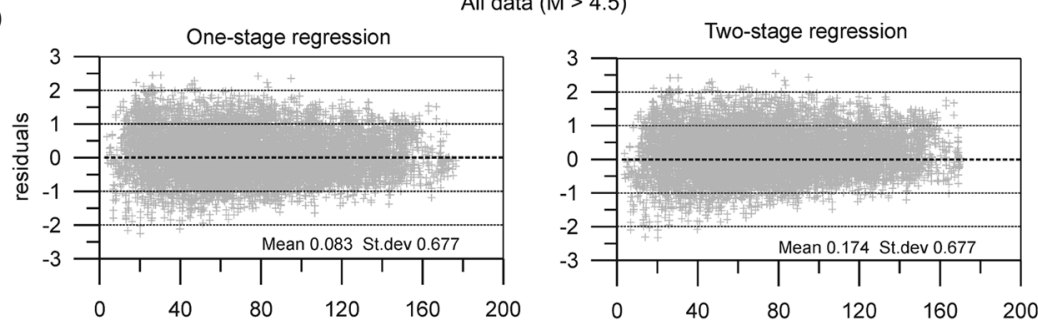

Large earthquakes $(M>6.5)$
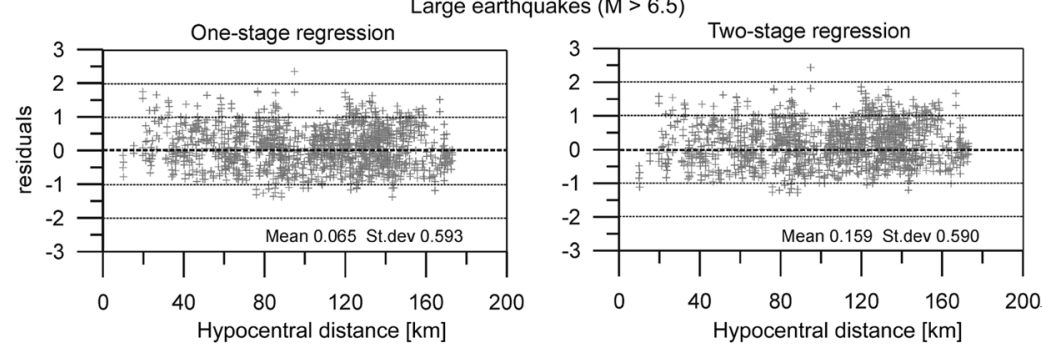

Fig. 5. Ground motion models estimated in this study using one-stage and two-stage regression [Eqs. (11a) and (11b)]. (a) PGA-distance distribution estimated for moment magnitudes 5.0,6.0 and 7.5. (b) Distribution of PGA residuals versus distance and statistical characteristics of the residuals. 
reason for the difference has been analyzed by Sokolov et al. $(2002,2003)$ who showed that the high and intermediate frequency (greater than $0.3-0.4 \mathrm{~Hz}$ ) radiation during the Chi-Chi earthquake and, at least, two large aftershocks were generated mainly from the fracture of small-scale fault heterogeneities. Thus, the relatively low near-field PGAs for large earthquakes in Taiwan are not surprising.

When comparing the rate of PGA attenuation with distance in far-field zone (slope of attenuation curve), it is seen that the 1SR model (line 1, Fig. 4), showing approximately the same rate as that in the Chang et al. (2001) model (line 4, Fig. 4), exhibits a smaller rate than that in the other models (lines 2, 3, 5, Fig. 4). This resulted in apparently high PGA values predicted by the 1SR model for far-field zone, especially for small and intermediate magnitude $\left(\mathrm{M}_{\mathrm{W}}\right.$ $<6.0$ ) earthquakes. Besides the possible biased estimations of regression coefficients, which may be obtained using the one-step regression, the phenomenon is caused by peculiarities of the ground motion data used. Only relatively large acceleration records were analyzed at longer distances because of a selection requirement (high signal-noise ratio, see Fig. 3). The resulting relatively low rate of ground motion attenuation will cause the larger level of predicted PGA than the actual average level at these distances. However the 1SR model, as has been mentioned earlier (see also Fig. 5) and will be shown later, provides unbiased residuals in a wide range of magnitude and distances. Thus, the model properly reflects the features of the particular database, which was used in this study. As we can see from comparison of different models shown in Fig. 4, application of the 1SR model for prediction of ground motion in Taiwan region would results in noticeably higher PGAs than the other model only for such magnitude-distance pairs, which are responsible for small PGA values $\left(<40-30 \mathrm{~cm} \mathrm{~s}^{-2}\right)$. The values are not significant for the hazard and loss estimations.

Note that the positive values of anelastic attenuation coefficient [term $b R$ in Eq. (10)], most likely, have been also caused by the peculiarities of the ground motion data used, which were mentioned above. On the other hand, the phenomenon may reflect a region- and/or azimuth-specific influence of the propagation path or site-specific effects (amplification) within the alluvium-filled Taipei basin and Ilan area.

The 1SR-model, which provides unbiased residuals in wide range of magnitude and distances, has been selected for further analyses. Note that inter-event correlation $\rho_{\eta}=\sigma_{\eta}^{2} / \sigma_{T}^{2}$ obtained in this study $\left(\rho_{\eta}=0.32\right)$ is almost the same as that $\left(\rho_{\eta}=0.30\right)$ estimated by Tsai et al. (2006)(see Table 1).

Morikawa et al. (2008) showed that uncertainty of a ground motion model may be reduced by grouping ground motion data at specific stations of dense strong-motion array. In our study we checked the result of such grouping considering particular arrays (TAP, TCU, CHY, and ILA), as well as particular site classes within the arrays.

For this purpose, the residuals between observed $Y_{i, j}$ and predicted $\bar{Y}_{i, j}$ amplitude $\delta_{i, j}$ were calculated for a given group of stations as $\delta_{i, j}=\log Y_{i, j}-\log \bar{Y}_{i, j}$ for earthquake $i$ and site $j$. The average group-dependent correction factor $D$ is considered to be a function of magnitude $\mathrm{M}_{\mathrm{w}}$ and the hypocentral distance $R$; and the function was estimated as

$D=a+b M_{W}+c R$

The results of the regression analysis of array- and sitedependent residuals are summarized in Table 2. Based on the $F$ ratio criterion, the dependence (12) should be considered as significant even for the cases of the smallest values for the coefficient for the multiple correlation. At the same time, some particular features of the correction factor are obvious. For example, in general the correction is negative for stations located on soft rock (class B), while soft soil (class E) stations require the highest values of positive correction. Also the class E stations, which are located within alluvium-filled areas (TAP and ILA arrays), are characterized by a prominent magnitude- and distance-dependent correction (the largest values of correlation coefficient). The phenomenon, most likely, reflects peculiarities of alluvium basins response during earthquakes of different magnitudes and location (e.g., Wen and Peng 1998; Lee et al. 2009; Sokolov et al. 2009).

The correction factor was applied together with the generalized ground-motion model [Eq. (11a)] for prediction of the group-dependent amplitude $\log \bar{Y} D_{i, j}=\log \bar{Y}_{i, j}+$ $D\left(M_{W}, R\right)$; and the residuals $\delta d_{i, j}=\log Y_{i, j}-\log \bar{Y} D_{i, j}$ were analyzed to estimate the group-dependent intra-event and inter-event components. Table 3 and Fig. 6 show influence of the correction on characteristics of residuals. Application of the correction factors reduces uncertainty, both the inter-event and the intra-event components. The reduction depends on region (array) and in some cases (TAP array) the reduction of standard deviation may reach a value of 0.85 . The reduction of uncertainty is especially prominent $(0.8)$ for the case of large $\left(M_{W}>7.0\right)$ earthquakes.

Figure 7 compares estimations of total standard deviation $\sigma_{T}$ and inter-event component $\sigma_{\eta}$ of residuals obtained without the array- and site-dependent correction and after the correction. The total residuals exhibit a magnitude-dependent trend, while the inter-event component seems to be a magnitude-independent characteristic. Thus, the correction reduces the intra-event component of residuals and, therefore, increases the ratio $\sigma_{\eta}^{2} / \sigma_{T}^{2}$ (inter-event correlation). It seems also that the characteristics of residuals are of the array- or region-dependent quantities (Table 3); however, the phenomenon may be caused by different numbers of events and of records collected by the considered arrays (see also Tsai et al. 2006). 
In this study we used the site classification proposed for TSMIP stations by Lee et al. (2001). The classification is under revision at present (e.g., Huang et al. 2005; Kuo et al. 2010). Therefore the equations of site-dependent correction should be considered as preliminary, the form and coefficients of which require further analysis.

\subsection{Estimation of Spatial Correlation}

Before evaluating the correlation models it is necessary to examine the homogeneity of logarithmic residuals $Z(x)=\log Y_{i j}-\log \bar{Y}_{i j}$, because we assumed that $Z(x)$ is a homogeneous 2D stochastic field (see section 2). In the considered case, homogeneity implies similarity of statistical properties (mean value and standard deviation) of the residuals for various distances and magnitudes. We analyzed the distance-dependent distribution of logarithmic residuals for several subsets of data, which contain data for different magnitude range. For this purpose, the mean values of
$Z(x)\left(M_{Z}\right)$ and standard deviation $\sigma_{z}$ of $Z(x)$ were calculated within a moving window of $20 \mathrm{~km}$ length (see also Wang and Takada 2005). Distribution of $M_{Z}$ and $\sigma_{Z}$ functions for considered magnitude ranges and for the Chi-Chi earthquake is shown in Fig. 8a. As can be seen, the mean and standard deviation of logarithmic residuals shows no dependency on distance and magnitude, at least for magnitudes more 6.0. Therefore, the assumption of homogeneity may be accepted for the subset of data.

To investigate the spatial correlation of ground motion residuals, the analysis incorporated these steps (e.g., Boore et al. 2003): (1) select the data for particular earthquake; (2) compute separation distance $\Delta$ for all pairs of stations; (3) compute the differences $\ln Y_{i j}-\ln \bar{Y}_{i j}$; (4) divide the range of $\Delta$ into bins so that the separation distance in the same bin is within $\Delta \pm \delta / 2$; and (5) all pairs of sites that fall in the bin centered at $\Delta \mathrm{km}$ (i.e., the sites that are separated by a distance $\in(\Delta-\delta / 2, \Delta+\delta / 2)$ are used to compute correlation function $\rho(\Delta)$ [see Eqs. (5) - (7)]. To avoid a large

Table 2. Results of a regression analysis of array- and site-dependent residuals.

\begin{tabular}{|c|c|c|c|c|c|}
\hline \multirow{2}{*}{ Site classes } & \multirow{2}{*}{$\begin{array}{l}\text { Mean of } \\
\text { residuals }\end{array}$} & \multirow{2}{*}{$\begin{array}{c}\text { Coefficient of } \\
\text { multiple } \\
\text { correlations }\end{array}$} & \multicolumn{3}{|c|}{ Coefficients of equation 12} \\
\hline & & & $a$ & $b$ & $c$ \\
\hline & \multicolumn{5}{|c|}{$\mathrm{CHY}$ array } \\
\hline Generalized for all site classes & 0.14 & 0.25 & -0.549 & 0.163 & -0.00319 \\
\hline Site class B & -0.25 & 0.41 & -1.792 & 0.317 & -0.00372 \\
\hline Site class C & -0.11 & 0.26 & -1.363 & 0.268 & -0.00386 \\
\hline Site class D & 0.17 & 0.37 & -0.913 & 0.271 & -0.00644 \\
\hline \multirow[t]{2}{*}{ Site class E } & 0.27 & 0.41 & -0.075 & 0.093 & -0.00229 \\
\hline & \multicolumn{5}{|c|}{ ILA array } \\
\hline Generalized for all site classes & 0.13 & 0.26 & -0.845 & 0.182 & -0.00186 \\
\hline Site class B & 0.11 & 0.42 & 0.892 & -0.046 & -0.00670 \\
\hline Site class C & - & - & - & - & - \\
\hline Site class D & 0.06 & 0.24 & -1.039 & 0.192 & -0.00053 \\
\hline \multirow[t]{2}{*}{ Site class E } & 0.25 & 0.5 & -1.892 & 0.371 & -0.00203 \\
\hline & \multicolumn{5}{|c|}{ TAP array } \\
\hline Generalized for all site classes & 0.013 & 0.38 & -1.983 & 0.301 & 0.00147 \\
\hline Site class B & -0.22 & 0.47 & -1.754 & 0.273 & -0.00142 \\
\hline Site class C & 0.18 & 0.38 & -1.272 & 0.216 & 0.00110 \\
\hline Site class D & 0.02 & 0.37 & -1.836 & 0.291 & 0.00099 \\
\hline \multirow[t]{2}{*}{ Site class E } & 0.12 & 0.61 & -3.021 & 0.505 & 0.00055 \\
\hline & \multicolumn{5}{|c|}{ TCU array } \\
\hline Generalized for all site classes & -0.07 & 0.22 & -0.394 & 0.076 & 0.00085 \\
\hline Site class B & -0.32 & 0.47 & -1.402 & 0.154 & 0.00196 \\
\hline Site class C & 0.21 & 0.44 & -1.879 & 0.282 & 0.00313 \\
\hline Site class D & 0.13 & 0.25 & -0.414 & 0.086 & 0.00034 \\
\hline Site class E & 0.23 & 0.35 & 0.809 & -0.101 & -0.00002 \\
\hline
\end{tabular}


Table 3. Characteristics of residuals obtained using the generalized model for ground motion [Eq. (11a)] and applying the array- and site-dependent correction. Values in parentheses show the degree of reduction of standard deviation $R=\sigma_{C R} / \sigma_{N C}$, where $\sigma_{N C}$ and $\sigma_{C R}$ are the standard deviations of residuals the case of uncorrected and corrected data, respectively.

\begin{tabular}{|c|c|c|c|c|c|}
\hline $\begin{array}{l}\text { Group (array, site class) } \\
\text { and function } D\left(M_{W}, R\right)\end{array}$ & $\begin{array}{c}\text { Number of } \\
\text { events and } \\
\text { records }\end{array}$ & $\begin{array}{c}\text { Total st. } \\
\text { deviation } \\
\sigma_{T}\end{array}$ & $\begin{array}{c}\text { Inter-event } \\
\text { deviation } \\
\sigma_{\eta}\end{array}$ & $\begin{array}{c}\text { Intra-event } \\
\text { deviation } \\
\sigma_{\varepsilon}\end{array}$ & $\begin{array}{c}\text { Ratio } \\
\rho_{\eta}=\sigma_{\eta}^{2} / \sigma_{T}^{2}\end{array}$ \\
\hline & & & All data & & \\
\hline No correction & $66 / 4656$ & 0.66 & 0.37 & 0.55 & 0.31 \\
\hline Generalized array-dependent correction & - & $0.62(0.93)$ & $0.35(0.93)$ & $0.51(0.95)$ & 0.32 \\
\hline \multirow[t]{2}{*}{ Array- and site-dependent correction } & - & $0.6(0.9)$ & $0.35(0.93)$ & $0.49(0.89)$ & 0.34 \\
\hline & & & TAP array & & \\
\hline No correction & $26 / 771$ & 0.60 & 0.37 & 0.47 & 0.38 \\
\hline Generalized array-dependent correction & - & $0.55(0.9)$ & $0.33(0.89)$ & $0.44(0.92)$ & 0.36 \\
\hline \multirow[t]{2}{*}{ Array- and site-dependent correction } & - & $0.52(0.87)$ & $0.33(0.89)$ & $0.40(0.85)$ & 0.40 \\
\hline & & & CHY array & & \\
\hline No correction & $42 / 1751$ & 0.69 & 0.44 & 0.54 & 0.40 \\
\hline Generalized array-dependent correction & - & $0.67(0.96)$ & $0.43(0.98)$ & $0.51(0.94)$ & 0.41 \\
\hline \multirow[t]{2}{*}{ Array- and site-dependent correction } & - & $0.64(0.93)$ & $0.41(0.93)$ & $0.49(0.91)$ & 0.41 \\
\hline & & & TCU array & & \\
\hline No correction & $28 / 741$ & 0.65 & 0.40 & 0.51 & 0.38 \\
\hline Generalized array-dependent correction & - & $0.62(0.96)$ & $0.39(0.97)$ & $0.49(0.95)$ & 0.40 \\
\hline \multirow[t]{2}{*}{ Array- and site-dependent correction } & - & $0.61(0.93)$ & $0.39(0.97)$ & $0.47(0.92)$ & 0.41 \\
\hline & & & ILA array & & \\
\hline No correction & $25 / 527$ & 0.65 & 0.45 & 0.47 & 0.48 \\
\hline Generalized array-dependent correction & - & $0.63(0.96)$ & $0.44(0.97)$ & $0.45(0.95)$ & 0.48 \\
\hline Array- and site-dependent correction & - & $0.60(0.92)$ & $0.42(0.94)$ & $0.42(0.91)$ & 0.49 \\
\hline
\end{tabular}

(a)

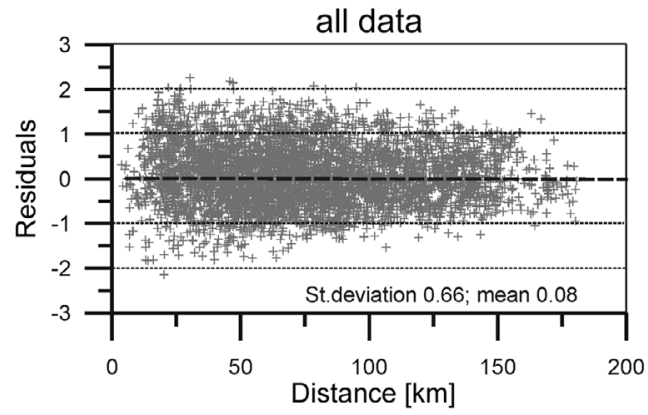

(b)

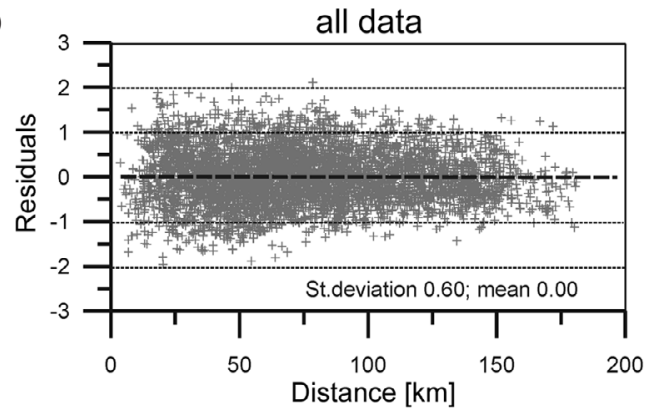

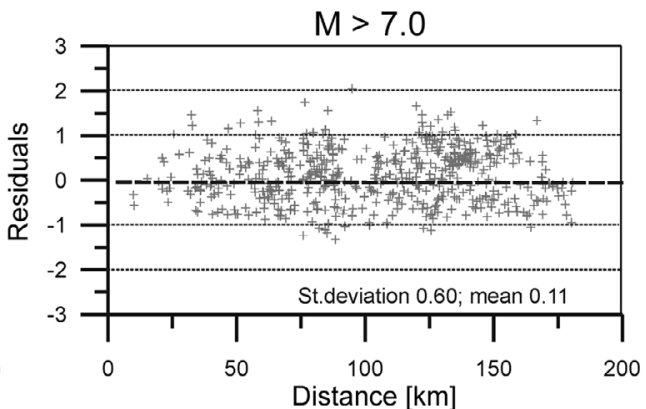

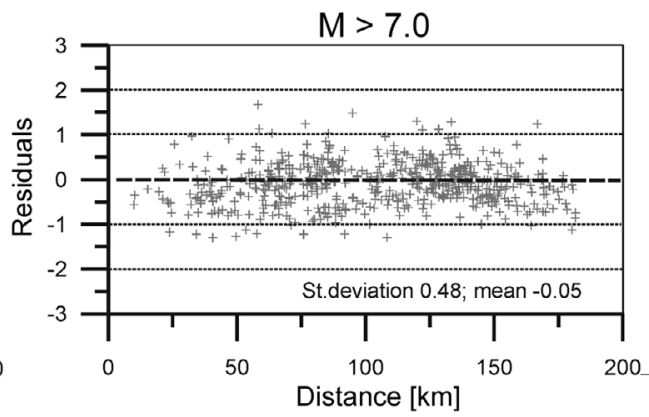

Fig. 6. Distribution of residuals between observed and predicted PGA values. Results obtained without the array- and site-dependent correction (a); and after the correction (b) [Eq. (12), Table 2]. 


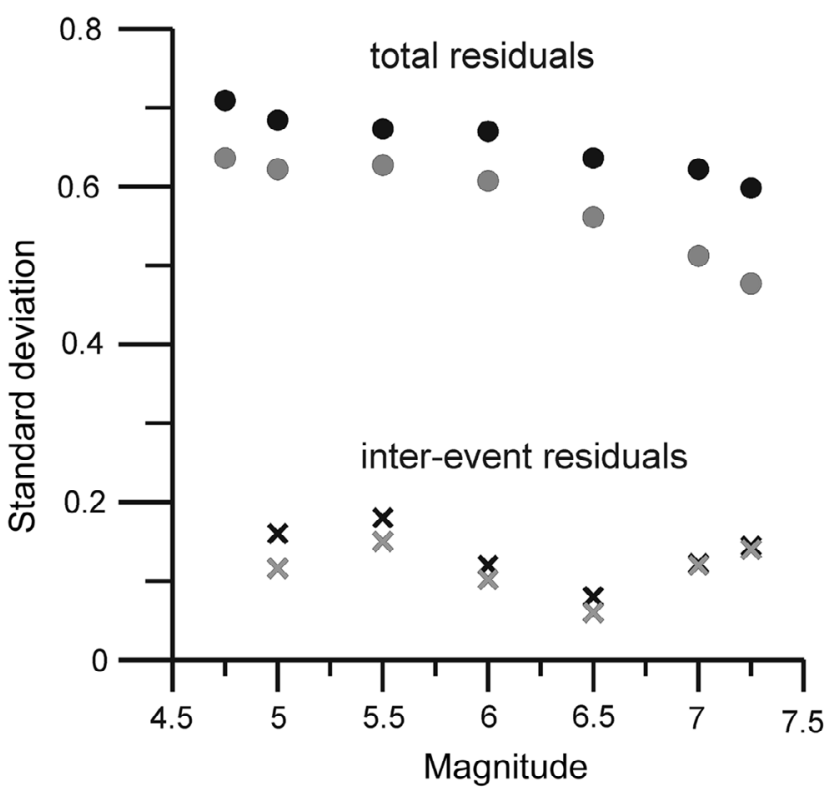

Fig. 7. Distribution of standard deviation of total residuals $\sigma_{T}$ (circles) and inter-event component $\sigma_{\eta}$ (crosses) versus magnitude estimated without the array- and site-dependent correction (black) and after the correction (grey). Standard deviation values were calculated for the data within particular magnitude ranges $\left(\mathrm{M}_{\mathrm{i}} \pm 0.5\right)$. Note that estimates for $\mathrm{M}_{\mathrm{W}}=4.75$ were obtained for range $\mathrm{M}_{\mathrm{W}} 4.5$ - 5.0 and estimates for $M_{W}=7.25$ were obtained for range $M_{W} 7.1$ - 7.6.

statistical error and to ensure the robustness of the results, only the data from moderate-to-large earthquakes $\left(\mathrm{M}_{\mathrm{W}}>\right.$ 6.0), which produced a large number of records, were considered in the analysis and a bin width of $4 \mathrm{~km}$ was used to group the data. Figure $8 \mathrm{~b}$ shows histogram of the data pairs for the earthquakes.

Let us consider the data from the largest recorded earthquake in Taiwan - the 1999 Chi-Chi earthquake. Figure 9a compares correlation functions $\rho_{\varepsilon}(\Delta)$ for the earthquake estimated in this work with those obtained by Wang and Takada (2005) and Goda and Hong (2008b). So-called "correlation length" may be considered as a characteristic of the correlation. Correlation length equals site-to-site distance, for which the correlation coefficient $\rho_{\varepsilon}(\Delta)$ becomes $1 / \mathrm{e} \cong$ 0.368 . Table 4 summarizes the values of correlation length estimated for particular large earthquakes.

The difference between the estimated correlation functions is obvious. Among the possible reasons of the difference we may mention that different ground-motion prediction models, as well as different ground motion parameters, were used for the analysis. The models developed for Japan and the maximum value of horizontal peak velocity amplitudes (PGV) was considered by Wang and Takada (2005). The NGA model based on worldwide data (Boore and Atkinson 2008) and average horizontal acceleration was used by Goda and Hong (2008b). Our results were obtained considering the geometric averages of two horizontal peak amplitudes and the regional strong-motion prediction equa- (a)
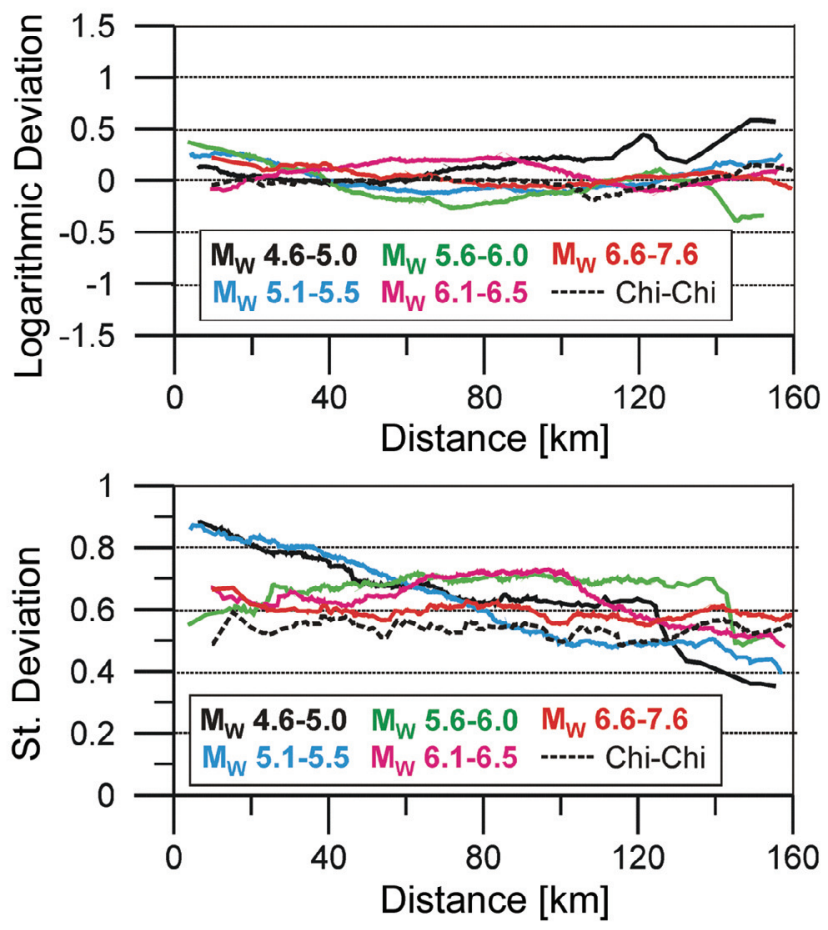

(b)

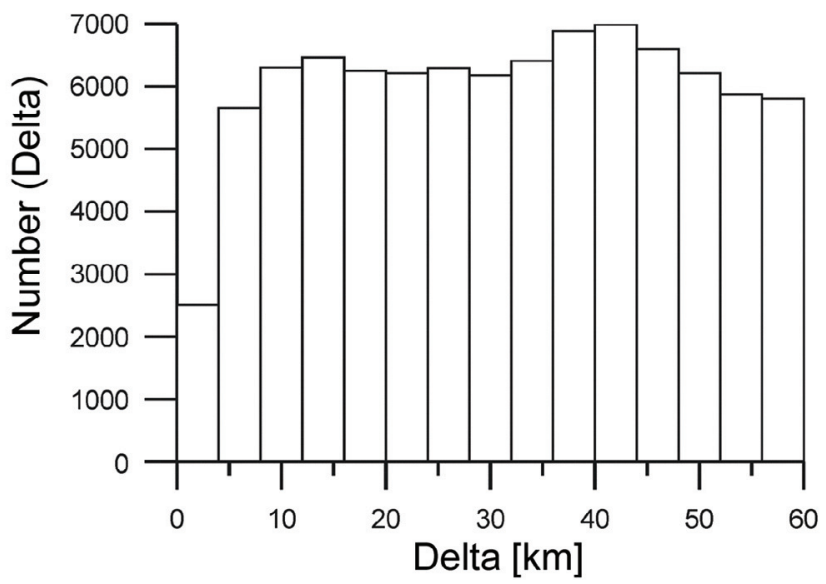

Fig. 8. Analysis of data from moderate-to-large earthquakes, $M_{W}>$ 6.0 to estimate spatial correlation. (a) Homogeneity of logarithmic deviation, moving averages of mean values and standard deviation, for particular magnitude ranges and separately for the Chi-Chi earthquake. (b) Histogram of the data pairs for separation distance.

tion for peak ground acceleration. Note that the possible influence of variations of the estimated correlation functions on seismic loss estimations for two buildings separated by $10 \mathrm{~km}$ has been analyzed by Goda and Atkinson (2009).

It has been noted above, that the array- and site-dependent correction factor has been evaluated [Eq. (12), Table 2] to be used together with the generalized model [Eq. (11a)] for prediction of ground motion parameters. The correlation function $\rho_{\varepsilon}(\Delta)$ was also estimated after application of the correction to the Chi-Chi earthquake data. As expected, the correction reduces the spatial site-to-site correlation 
(a)

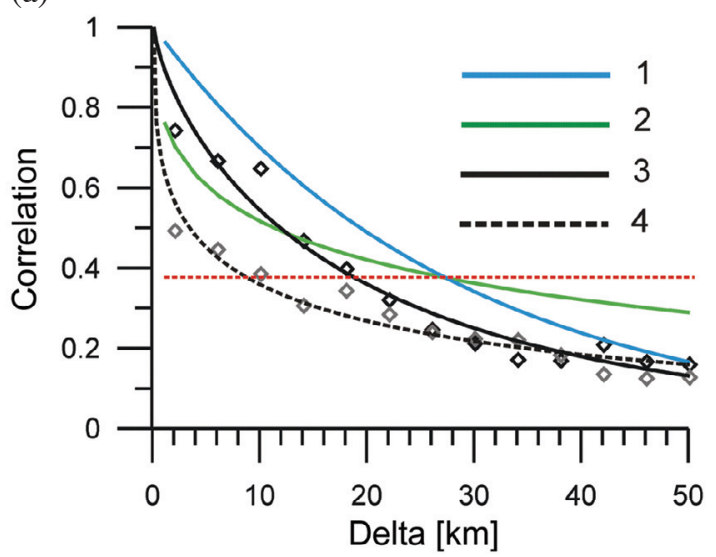

(c)

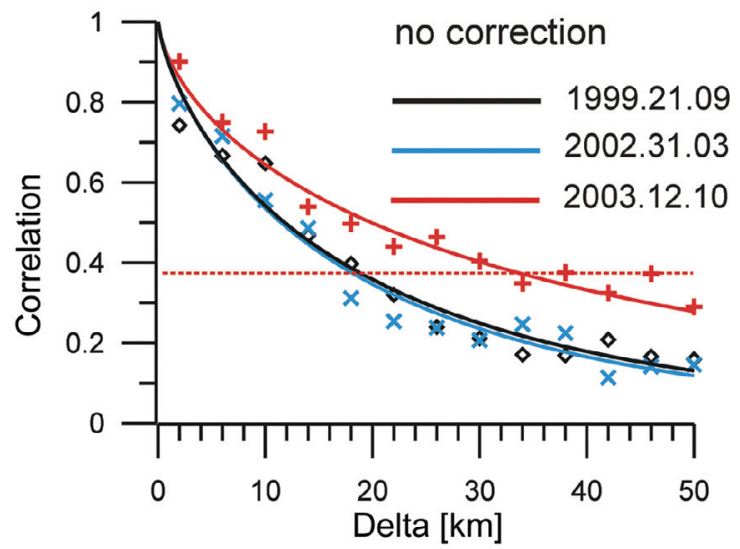

(b)

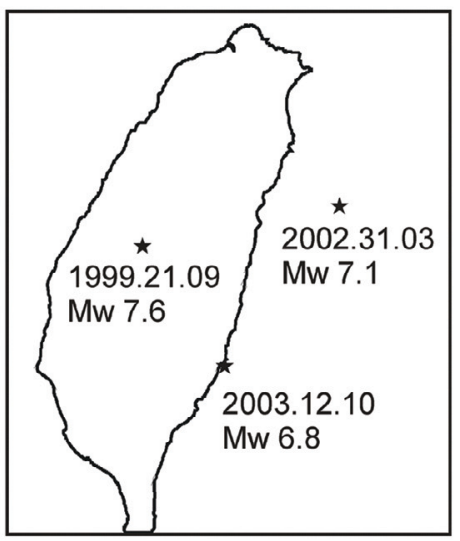

(d)

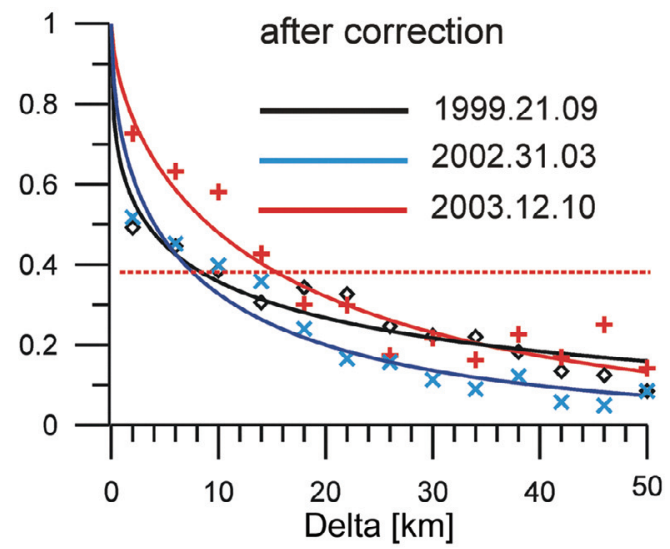

Fig. 9. Site-to-site intra-event (spatial) correlation functions $\rho_{\varepsilon}(\Delta)$ estimated for particular earthquakes. (a) The Chi-Chi earthquake, 1 - Wang and Takada (2005); 2 - Goda and Hong (2008a); 3 - this study, without the array- and site-dependent correction; 4 - this study, after the correction. (b) Location of particular large earthquakes, the data of which were analyzed. (c), (d) Spatial correlation functions estimated using records from the earthquakes separately without the array- and site-dependent correction (c) and after the correction (d). Red dashed line shows the level of correlation coefficient $\rho_{\varepsilon}(\Delta)=1 / e \cong 0.368$.

Table 4. Parameters of site-to-site intra-event correlation functions $\rho_{\varepsilon}(\Delta)=\exp \left(a \Delta^{b}\right)$ estimated for particular large earthquakes in Taiwan.

\begin{tabular}{|c|c|c|c|}
\hline \multirow{2}{*}{ Earthquake } & \multicolumn{2}{|c|}{ Coefficients } & \multirow{2}{*}{$\begin{array}{l}\text { Correlation } \\
\text { length }[\mathbf{k m}]\end{array}$} \\
\hline & $a$ & $b$ & \\
\hline & \multicolumn{3}{|c|}{ No correction } \\
\hline Chi-Chi, 1999.09.21 & -0.275 & 0.468 & 18 \\
\hline 2002.03 .31 & -0.108 & 0.763 & 18 \\
\hline \multirow[t]{2}{*}{2003.12 .10} & -0.095 & 0.663 & 34 \\
\hline & \multicolumn{3}{|c|}{ after correction } \\
\hline Chi-Chi, 1999.09.21 & -0.448 & 0.360 & 8 \\
\hline 2002.03 .31 & -0.331 & 0.527 & 8 \\
\hline \multirow[t]{2}{*}{2003.12 .10} & -0.173 & 0.628 & 15 \\
\hline & \multicolumn{3}{|c|}{ Wang and Takada 2005} \\
\hline \multirow[t]{2}{*}{ Chi-Chi, 1999.09.21 } & -0.038 & 1.0 & 27 \\
\hline & \multicolumn{3}{|c|}{ Goda and Hong 2008b } \\
\hline Chi-Chi, 1999.09.21 & -0.27 & 0.39 & 27 \\
\hline
\end{tabular}

(Fig. 9a). The spatial correlation should decrease for the sites that do not share the same geology, or for the sites that are not affected by similar site effect. The purpose of the correction is to eliminate, even if partially, any influence of the site condition. Ideally, the perfect site-dependent correction should provide a zero coefficient of spatial correlation at non-zero separation distances.

The functions of spatial correlation $\rho_{\varepsilon}(\Delta)$ were also analyzed separately for three large earthquakes occurred in different parts of Taiwan (Fig. 9b). The correlation functions estimated for these earthquakes without array- and site-dependent correction and after the correction are shown in Figs. $9 \mathrm{c}$ and d, respectively. The function $\rho_{\varepsilon}(\Delta)$ estimated from the records of the 2003 earthquake, which occurred in the southern part of the island, is characterized by a larger correlation length than that for the functions estimated from the data of the 1999 event (the Chi-Chi earthquake) and the 2002 event. The data from the 1999 event contain records obtained by stations from all TSMIP arrays (see Fig. 1b); the data from the 2002 event contain records from almost 
all arrays except the TTN and KAU arrays; and the data from the 2003 event contain records obtained by the CHY, TTN, and TCU arrays. It seems that the spatial correlation of ground motion in Taiwan exhibits an array-dependent (or region-dependent) character.

It is also necessary to bear in mind the azimuth-dependent influence of the propagation path. The largest part of the data documenting the 2003 event, which is characterized by the highest values of spatial correlation function, was obtained toward the North of the earthquake source. The relatively high level of the site-to-site correlation at large distances for this event (Fig. 9c) indicates that, besides a geological factor, there is an additional source of similarity of ground motion residuals, for example the earthquakespecific influence of the rupture propagation, or regionspecific influence of the propagation path. Application of the array- and site-dependent correction reduced the site-tosite correlation for the event, especially at large distances (Fig. 9d, Table 4).

We used a dataset from the 13 largest $\left(\mathrm{M}_{\mathrm{W}}>6.0\right)$ earthquakes (Fig. 10a) in our database to estimate the spatial correlation functions $\rho_{\varepsilon}(\Delta)$ separately for several arrays: the CHY, ILA, TAP, and TCU arrays (see Fig. 1b). As it has been noted earlier (see section 2), in this case of simultaneous consideration of several earthquakes the interevent component of residuals was removed using Eq. (10). Figures $10 \mathrm{~b}$ and $\mathrm{c}$ compare the array-dependent functions of spatial correlation and Table 5 summarizes parameters of the functions. The comparison clearly reveals influence of peculiarities of local geological conditions on site-to-site correlation. The CHY array is located on so-called Chianan Plain - an area of thick sediments, from central west to southwestern Taiwan; most stations of the ILA and the
TAP arrays are installed within alluvium-filled basins with relatively rapid lateral changes of depth of sediments; the stations of TCU array are located partly on the northern part of Chianan Plain and hilly areas in Northwestern Taiwan.

Thus, the correlation of ground motion depends on spatial variability of geological characteristics of the area. The parameters of the function $\rho_{\varepsilon}(\Delta)$, e.g., correlation length, plays an important role when estimating the losses. Sokolov and Wenzel (2009) showed that large correlation distances in spatial correlation lead to the increase of variability of possible loss. At the same the smaller correlation distances lead to the larger median values of possible loss.

\section{CONCLUSION}

In this work we analyzed characteristics of aleatory variability for strong ground motion prediction in Taiwan and spatial correlation of ground motion. The characteristics are very important for assessment of seismic hazard and loss for regionally located building assets (portfolio) and spatially distributed systems (lifelines) and ShakeMap generation. The strong-motion database collected by the TSMIP network in Taiwan, which includes about 4650 records from 66 shallow earthquakes $\left(\mathrm{M}_{\mathrm{L}}>4.5\right.$, focal depth $<30$ $\mathrm{km}$ ), which occurred between 1993 - 2004, were used for the purpose. The ground motion prediction equation, which was applied for calculation of ground motion residuals, has been developed in this study and it describes dependence of geometric mean of peak ground acceleration (PGA) of two horizontal components on moment magnitude and hypocentral distance.

The characteristics of ground motion uncertainty estimated in this study using the generalized prediction model (a)

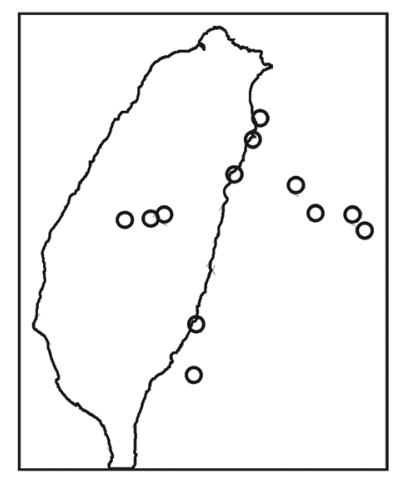

(b)

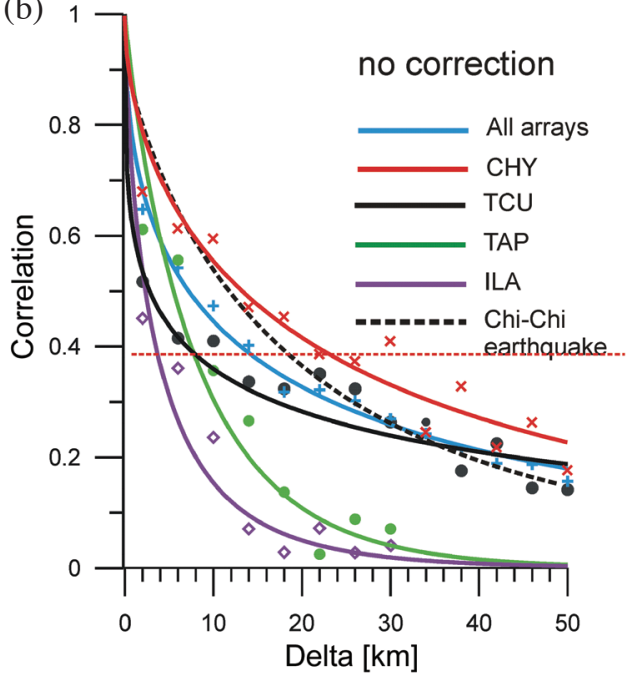

(c)

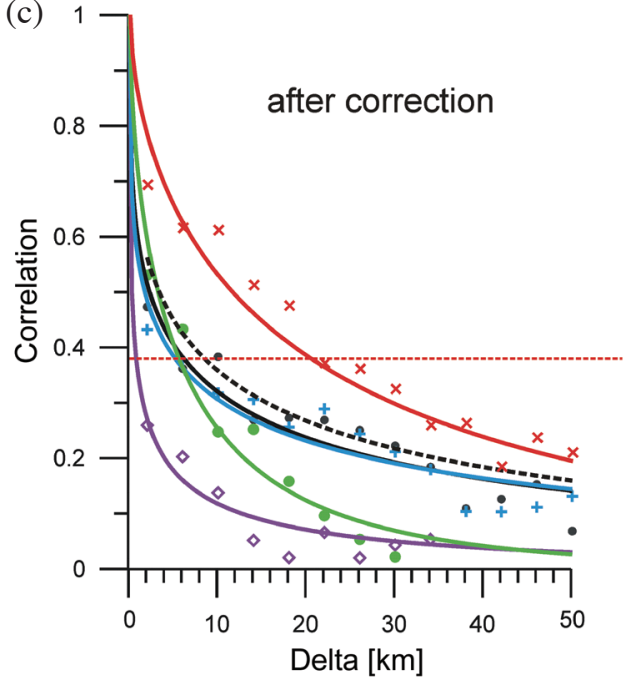

Fig. 10. Site-to-site intra-event (spatial) correlation functions for particular strong-motion arrays in Taiwan estimated using data from moderate-tolarge earthquakes $\left(\mathrm{M}_{\mathrm{W}}>6.0\right)$. (a) Location of the earthquakes. (b), (c) Spatial correlation functions estimated without the array- and site-dependent correction (b) and after the correction (c). Red dashed line shows the level of correlation coefficient $\rho_{\varepsilon}(\Delta)=1 / e \cong 0.368$. 
Table 5. Parameters of site-to-site intra-event correlation functions $\rho_{\varepsilon}(\Delta)=\exp \left(a \Delta^{b}\right)$ estimated for particular TSMIP arrays in Taiwan.

\begin{tabular}{|c|c|c|c|c|}
\hline \multirow{2}{*}{ Array } & \multicolumn{2}{|c|}{ Coefficients $*$} & \multirow{2}{*}{$\begin{array}{l}\text { Correlation } \\
\text { length* }\end{array}$} & \multirow{2}{*}{ A short description of the geology } \\
\hline & $a$ & $b$ & & \\
\hline All data & $\begin{array}{l}-0.275 \\
(-0.586)\end{array}$ & $\begin{array}{c}0.468 \\
(0.306)\end{array}$ & $14(6)$ & $\begin{array}{l}\text { Taiwan island was uplifted by the collision and subduction effect between the } \\
\text { Philippine Sea Plate and the Eurasian Plate, and TSMIP stations are mostly } \\
\text { installed on sediments, where all important cities were situated. }\end{array}$ \\
\hline $\mathrm{CHY}$ & $\begin{array}{l}-0.156 \\
(-0.165)\end{array}$ & $\begin{array}{c}0.574 \\
(0.587)\end{array}$ & $23(20)$ & $\begin{array}{l}\text { The array is located on the so-called Chianan Plain, in which the Quaternary } \\
\text { strata (total thickness may almost reach } 1500 \text { meters, e.g., Lin et al. 2009) } \\
\text { cover on the order complex geological traits. }\end{array}$ \\
\hline ILA & $\begin{array}{l}-0.391 \\
(-1.056)\end{array}$ & $\begin{array}{c}0.679 \\
(0.307)\end{array}$ & $4(2)$ & $\begin{array}{l}\text { Most stations are instrumented on the Quaternary alluvial Ilan basin, in which } \\
\text { the thickness of deposits may be more than } 1200 \text { meters in the central part. }\end{array}$ \\
\hline TAP & $\begin{array}{l}-0.149 \\
(-0.342)\end{array}$ & $\begin{array}{c}0.902 \\
(0.605)\end{array}$ & $8(6)$ & $\begin{array}{l}\text { Most part of ground motion stations located within Taipei basin - triangular } \\
\text { asymmetric alluvium filled basin; thickness of sediments in the deepest part of } \\
\text { the basin reaches } 700 \text { meters. The geological structure inside the basin consists } \\
\text { of Quaternary layers above tertiary base rock (e.g., Wang 2008). The TAP ar- } \\
\text { ray also includes several stations located to the East and South of the basin in } \\
\text { mountainous and hilly areas. }\end{array}$ \\
\hline TCU & $\begin{array}{l}-0.506 \\
(-0.527)\end{array}$ & $\begin{array}{c}0.306 \\
(0.366)\end{array}$ & $8(6)$ & $\begin{array}{l}\text { The stations are located on relatively stiff soils in extended hilly areas except } \\
\text { for Changhua County. }\end{array}$ \\
\hline
\end{tabular}

* no array- and site-dependent correction (after the correction).

[Eq. (11a)] and the array- and site dependent correction [Eq. (12), Table 2] are similar with the correspondent results (see Table 1) obtained by other authors. The total standard deviation in our model $\sigma_{T}$ after the correction is estimated to be 0.60 (ln PGA, g), while Cheng et al. (2007) obtained a value of 0.55 for soil sites. The estimations of inter-event correlation, or the ratio between the inter-event variation and the total variation $\sigma_{\eta}^{2} / \sigma_{T}^{2}$, are almost similar in our study and in the analysis performed by Tsai et al. (2006), that is 0.32 and 0.30 correspondingly. It seems that the total standard deviation of ground motion errors in Taiwan is a magnitude-dependent quantity.

We showed also that, when using the generalized ground motion prediction model, the uncertainty of prediction may be reduced by application of correspondent empirically-derived correction factor. For the Taipei basin, for example, Jean et al. (2006) used the station-dependent correction factor. Sokolov et al. (2009) and Miksat et al. (2010), among other, showed that the basin response depends not only on site location inside the basin, but also on the location of earthquake. Therefore, not only the site- or region-dependent correction but also the azimuth-dependent of path-dependent correction may be necessary. This may increase the number of model coefficients [Eq. (12)]. Obviously, any number of coefficients and types of equations may be easily incorporated into ground motion computations. However, a special analysis should be performed to justify statistical significance of increase of the model com- plexity. We plan to curry out such analysis in future using the revised site classification of TSMIP stations.

The knowledge of characteristics of spatial correlation and relation between the inter-event and intra-event variability is very important in estimations of parameters of loss distribution. Analysis of the site-to-site (or spatial) correlation in Taiwan allows us to draw a conclusion whereby we find the correlation structure is highly dependent on local geology and on peculiarities of propagation path (azimuthdependent attenuation)(see also Wang and Takada 2005). The application of a region- or site-dependent correction reduces the spatial correlation, especially at large distances. Thus, a single generalized model of spatial correlation may not be adequate for the whole Taiwan territory or large areas.

Future tasks include the need to evaluate the correlation structure for other parameters of ground motion, which are used for seismic loss assessments, namely: peak velocities (PGV), pseudo-acceleration spectra (PSA) at various natural vibration periods, and seismic intensity (JMA or MMI scale). The extended ground motion database, which includes earthquakes after 2004, should be used. This allows an increased number of records for various arrays and performing comprehensive analysis of correlation structure for various arrays (areas), site classes and geological structures (e.g., Taipei and Ilan basins, Chianan Plain). Applications of results of such thorough analysis for seismic loss calculations, both deterministic and probabilistic, as well as 
for the Shakemap generation, are highly desirable for an assessment of the influence of variations of correlation structures on such engineering applications.

Acknowledgements This work was sponsored by Deutsche Forschungsgemeinschaft (DFG), Germany (project WE 1394/14-1). The authors are grateful to Katsuichiro Goda for valuable comments and suggestions that allow improving the manuscript. The authors would like to thank the Central Weather Bureau of the Republic of China for providing TSMIP data.

\section{REFERENCES}

Abrahamson, N. and W. Silva, 2008: Summary of the Abrahamson \& Silva NGA ground-motion relations. Earthq. Spectra, 24, 67-97, doi: 10.1193/1.2924360. [Link]

Abrahamson, N., G. Atkinson, D. Boore, Y. Bozorgnia, K. Campbell, B. Chiou, I. M. Idriss, W. Silva, and R. Youngs, 2008: Comparisons of the NGA ground-motion relations. Earthq. Spectra, 24, 45-66, doi: 10.1193/ 1.2924363. [Link]

Abrahamson, N. A. and R. R. Youngs, 1992: A stable algorithm for regression analyses using the random effects model. Bull. Seismol. Soc. Am., 82, 505-510.

Baker, J. W. and N. Jayaram, 2008: Effects of spatial correlation of ground motion parameters for multi-site seismic risk assessment: Collaborative research with Stanford University and AIR. Final Technical Report for US Geological Survey National Earthquake Hazards Reduction Program (NEHRP) External Research Program Award 07HQGR0031, 69 pp.

Bommer, J. J. and H. Crowley, 2006: The influence of ground-motion variability in earthquake loss modelling. Bull. Earthq. Eng., 4, 231-248, doi: 10.1007/s 105 18-006-9008-z. [Link]

Bommer, J. J., F. Scherbaum, H. Bungum, F. Cotton, F. Sabetta, and N. A. Abrahamson, 2005: On the use of logic trees for ground-motion prediction equations in seismic-hazard analysis. Bull. Seismol. Soc. Am., 95, 377-389, doi: 10.1785/0120040073. [Link]

Boore, D. M., 2001: Comparisons of ground motions from the 1999 Chi-Chi earthquake with empirical predictions largely based on data from California. Bull. Seismol. Soc. Am., 91, 1212-1217, doi: 10.1785/0120000733. [Link]

Boore, D. M. and G. M. Atkinson, 2008: Ground-motion prediction equations for the average horizontal component of PGA, PGV, and 5\%-damped PSA at spectral periods between $0.01 \mathrm{~s}$ and $10.0 \mathrm{~s}$. Earthq. Spectra, 24, 99-138, doi: 10.1193/1.2830434. [Link]

Boore, D. M., W. B. Joyner, and T. E. Fumal, 1997: Equations for estimating horizontal response spectra and peak acceleration from western North American earth- quakes: A summary of recent work. Seismol. Res. Lett., 68, 128-153.

Boore, D. M., J. F. Gibbs, W. B. Joyner, J. C. Tinsley, and D. J. Ponti, 2003: Estimated ground motion from the 1994 Northridge, California, Earthquake at the site of the Interstate 10 and La Cienega Boulevard Bridge collapse, West Los Angeles, California. Bull. Seismol. Soc. Am., 93, 2737-2751, doi: 10.1785/0120020197. [Link]

Brillinger, D. R. and H. K. Preisler, 1984: An exploratory analysis of the Joyner-Boore attenuation data. Bull. Seismol. Soc. Am., 74, 1441-1450.

Brillinger, D. R. and H. K. Preisler, 1985: Further analysis of the Joyner-Boore attenuation data. Bull. Seismol. Soc. Am., 75, 611-614.

Building Seismic Safety Council (BSSC), 1998: 1997 Edition NEHRP recommended provisions for seismic regulations for new buildings and other structures, FEMA 302/303, Part 1 (Provisions) and Part 2 (Commentary), developed for the Federal Emergency Management Agency, Washington, DC.

Campbell, K. W., 1981: Near-source attenuation of peak horizontal acceleration. Bull. Seismol. Soc. Am., 71, 2039-2070.

Campbell, K. W., P. C. Thenhaus, T. P. Barnard, and D. B. Hampson, 2002: Seismic hazard model for loss estimation and risk management in Taiwan. Soil Dyn. Earthq. Eng., 22, 743-754, doi: 10.1016/S0267-7261 (02)00095-7. [Link]

Chang, T. Y., F. Cotton, and J. Angelier, 2001: Seismic attenuation and peak ground acceleration in Taiwan. Bull. Seismol. Soc. Am., 91, 1229-1246, doi: 10.1785/ 0120000729. [Link]

Cheng, C. T., S. J. Chiou, C. T. Lee, and Y. B. Tsai, 2007: Study of probabilistic seismic hazard maps of Taiwan after Chi-Chi earthquake. J. GeoEng., 2, 19-28.

Crowley, H., J. J. Bommer, and P. J. Stafford, 2008: Recent developments in the treatment of ground-motion variability in earthquake loss models. J. Earthqu. Eng., 12, 71-80, doi: 10.1080/13632460802013529. [Link]

Douglas, J., 2003: Earthquake ground motion estimation using strong-motion records: A review of equations for the estimation of peak ground acceleration and response spectral ordinates. Earth-Sci. Rev., 61, 43-104, doi: 10.1016/S0012-8252(02)00112-5. [Link]

Douglas, J., 2006: Errata and additions to "Ground motion estimation equations 1966-2003," BRGM/RP-54603FR, 103 pp.

EERI (Earthquake Engineering Research Institute), 2001: Chi-Chi Taiwan, Earthquake of September 21, 1999 Reconnaissance Report, Earthq. Spectra, (CD-ROM Supplement A), 17.

Evans, J. R. and J. W. Baker, 2006: Spatial Correlation of Ground Motions in NGA Data. Eos, Trans., AGU, 87 (52), Fall Meet. Suppl., Abstract S12B-01. 
Fukushima, Y. and T. Tanaka, 1990: A new attenuation relation for peak horizontal acceleration of strong earthquake ground motion in Japan. Bull. Seismol. Soc. Am., 80, 757-783.

Goda, K. and H. P. Hong, 2008a: Estimation of seismic loss for spatially distributed buildings. Earthq. Spectra, 24, 889-910, doi: 10.1193/1.2983654. [Link]

Goda, K. and H. P. Hong, 2008b: Spatial correlation of peak ground motions and response spectra. Bull. Seismol. Soc. Am., 98, 354-365, doi: 10.1785/0120070078. [Link]

Goda, K. and G. M. Atkinson, 2009: Probabilistic characterization of spatially correlated response spectra for earthquakes in Japan. Bull. Seismol. Soc. Am., 99, 3003-3020, doi: 10.1785/0120090007. [Link]

Hok, S. and D. J. Wald, 2003: Spatial variability of peak strong ground motions: Implications for ShakeMap interpolations. Eos, Trans., AGU, 84, F1121.

Hong, H. P., Y. Zhang, and K. Goda, 2009: Effect of spatial correlation on estimated ground-motion prediction equations. Bull. Seismol. Soc. Am., 99, 928-934, doi: 10.1785/0120080172. [Link]

Huang, M. W., J. H. Wang, H. H. Hsieh, K. L. Wen, and K. F. Ma, 2005: Frequency-dependent sites amplifications evaluated from well-logging data in Central Taiwan. Geophys. Res. Lett., 32, L21302, doi: 10.1029/ 2005GL023527. [Link]

Jayaram, N. and J. W. Baker, 2009: Correlation model for spatially distributed ground-motion intensities. Earthq. Eng. Struct. Dyn., 38, 1687-1708, doi: 10.1002/eqe.922. [Link]

Jean, W. Y., Y. W. Chang, K. L. Wen, and C. H. Loh, 2006: Early estimation of seismic hazard for strong earthquakes in Taiwan. Nat. Hazards, 37, 39-53, doi: 10.1007/s11069-005-4655-y. [Link]

Joyner, W. B. and D. M. Boore, 1981: Peak horizontal acceleration and velocity from strong-motion records including records from the 1979 Imperial Valley, California, earthquake. Bull. Seismol. Soc. Am., 71, $2011-$ 2038.

Joyner, W. B. and D. M. Boore, 1993: Methods for regression analysis of strong-motion data. Bull. Seismol. Soc. Am., 83, 469-487.

Kanno, T., A. Narita, N. Morikawa, H. Fujuwara, and Y. Fukushima, 2006: A new attenuation relation for strong ground motion in Japan based on recorded data. Bull. Seismol. Soc. Am., 96, 879-897, doi: 10.1785/0120050138. [Link]

Kawakami, H. and H. Mogi, 2003: Analyzing spatial intraevent variability of peak ground accelerations as a function of separation distance. Bull. Seismol. Soc. Am., 93, 1079-1090, doi: 10.1785/0120020026. [Link]

Kuo, C. H, K. L. Wen, H. H. Hsieh, T. M. Chang, C. M. Lin, and C. T. Chen, 2010: Evaluating empirical re- gression equations for $V s$ and estimating $V s 30$ in northeastern Taiwan. Soil Dyn. Earthq. Eng., in press, doi: 10.1016/j.soildyn.2010.09.012. [Link]

Lee, C. T., C. T. Cheng, C. W. Liao, and Y. B. Tsai, 2001: Site classification of Taiwan free-field strong-motion stations. Bull. Seismol. Soc. Am., 91, 1283-1297, doi: 10.1785/0120000736. [Link]

Lee, R., A. S. Kiremidjian, and E. Stergiou, 2004: Uncertainty and correlation of network components losses for a spatially distributed system. Proc. 13th World Conference on Earthquake Engineering, Vancouver, Canada, August 1-6, Paper 989.

Lee, S. J., D. Komatitsch, B. S. Huang, and J. Tromp, 2009: Effects of topography on seismic-wave propagation: An example from northern Taiwan. Bull. Seismol. Soc. Am., 99, 314-325, doi: 10.1785/0120080020. [Link]

Lin, C. M., T. M. Chang, Y. C. Huang, H. J. Chiang, C. H. Kuo, and K. L. Wen, 2009: Shallow S-wave velocity structures in the western coastal plain of Taiwan. Terr. Atmos. Ocean. Sci., 20, 299-308, doi: 10.3319/ TAO.2007.12.10.01(T). [Link]

Lin, K. W., D. Wald, B. Worden, and A. F. Shakal, 2006: Progress toward quantifying CISN ShakeMap uncertainty. Eighth National Conference on Earthquake Engineering, San Francisco, California, April 18-21, 2006.

Lin, P. S. and C. T. Lee, 2008: Ground-motion attenuation relationships for subduction-zone earthquakes in northeastern Taiwan. Bull. Seismol. Soc. Am. 98, 220240, doi: 10.1785/0120060002. [Link]

Liu, K. S and Y. B. Tsai, 2005: Attenuation relationships of peak ground acceleration and velocity for crustal earthquakes in Taiwan. Bull. Seismol. Soc. Am., 95, $1045-$ 1058, doi: 10.1785/0120040162. [Link]

McVerry, G. H., D. A. Rhoades, and W. D. Smith, 2004: Joint hazard of earthquake shaking at multiple locations. Proc. $13^{\text {th }}$ World Conference on Earthquake Engineering, Vancouver, Canada, August 1-6, 2004, Paper 646.

Miksat, J., K. L. Wen, V. Sokolov, C. T. Chen, and F. Wenzel, 2010: Simulating the Taipei basin response by numerical modeling of wave propagation. Bull. Earthq. Eng., 8, 847-858, doi: 10.1007/s10518-009-91 71-0. [Link]

Molas, G. L., R. Anderson, P. Seneviratna, and T. Winkler, 2006: Uncertainty of portfolio loss estimates for large earthquakes. Proc. First European Conference on Earthquake Engineering and Seismology, Geneva, Switzerland, 3-8 September 2006, Paper 1117.

Morikawa, N., T. Kanno, A. Narita, H. Fujiwara, T. Okumura, Y. Fukushima, and A. Guerpinar, 2008: Strong motion uncertainty determined from observed records by dense network in Japan. J. Seismol., 12, 529-546, doi: 10.1007/s10950-008-9106-2. [Link] 
Park, J., P. Bazzurro, and J. W. Baker, 2007: Modeling spatial correlation of ground motion Intensity Measures for regional seismic hazard and portfolio loss estimation. In: Kanda, J., T. Takada, and H. Furuta (Eds.), Applications of Statistics and Probability in Civil Engineering, Taylor \& Francis Group, London, 1-8.

Power, M., B. Chiou, N. Abrahamson, Y. Bozorgnia, T. Shantz, and C. Roblee, 2008: An overview of the NGA Project. Earthq. Spectra, 24, 3-21, doi: 10.1193/1.289 4833. [Link]

Reiter, R., 1990: Earthquake Hazard Analysis: Issues and Insight. Columbia University Press, New York.

Rhoades, D. A. and G. H. McVerry, 2001: Joint hazard of earthquake shaking at two or more locations. Earthq. Spectra, 17, 697-710, doi: 10.1193/1.1423903. [Link]

Sokolov, V. and F. Wenzel, 2009: Spatial correlation of strong ground motion and uncertainty in earthquake loss estimation. 95 Journees Luxembourgeoises de Geodynamique, Echternach, Luxembourg, 9-11 November 2009.

Sokolov, V., C. H. Loh, and K. L. Wen, 2002: Evaluation of models for Fourier amplitude spectra for the Taiwan region. Soil Dyn. Earthq. Eng., 22, 719-731, doi: 10.1016/S0267-7261(02)00026-X. [Link]

Sokolov, V., C. H. Loh, and K. L. Wen, 2003: Evaluation of hard rock spectral models for the Taiwan region on the basis of the 1999 Chi-Chi earthquake data. Soil Dyn. Earthq. Eng., 23, 715-735, doi: 10.1016/S02677261(03)00075-7. [Link]

Sokolov, V., C. H. Loh, and K. L. Wen, 2004: Evaluation of generalized site response functions for typical soil classes (B, C, and D) in Taiwan. Earthq. Spectra, 20, 1279-1316, doi: 10.1193/1.1814121. [Link]
Sokolov, V., K. L. Wen, J. Miksat, F. Wenzel, and C. T. Chen, 2009: Analysis of Taipei basin response for earthquakes of various depths and locations using empirical data. Terr. Atmos. Ocean. Sci., 20, 687-702, doi: 10.3319/TAO.2008.10.15.01(T). [Link]

Strasser, F. O., N. A. Abrahamson, and J. J. Bommer, 2009: Sigma: Issues, insights, and challenges. Seismol. Res. Lett., 80, 40-56, doi: 10.1785/gssrl.80.1.40. [Link]

Tsai, C. C. P., C. H. Loh, and Y. T. Yeh, 1987: Analysis of earthquake risk in Taiwan based on seismotectonic zones. Mem. Geol. Soc. China, 9, 413-446.

Tsai, C. C. P., Y. H. Chen, and C. H. Liu, 2006: The path effect in ground-motion variability: An application of the variance-components technique. Bull. Seismol. Soc. Am., 96, 1170-1176, doi: 10.1785/0120050155. [Link]

Tsai, Y. B. and M. W. Huang, 2000: Strong ground motion characteristics of the Chi-Chi, Taiwan earthquake of September 21, 1999. Earthq. Eng. Eng. Seismol., 2, $1-21$.

Wang, J. H., 2008: Urban seismology in the Taipei Metropolitan Area: Review and prospective. Terr. Atmos. Ocean. Sci., 19, 213-233, doi: 10.3319/TAO.2008.19. 3.213(T). [Link]

Wang, M. and T. Takada, 2005: Macrospatial correlation model of seismic ground motions. Earthq. Spectra, 21, 1137-1156, doi: 10.1193/1.2083887. [Link]

Wen, K. L. and H. Y. Peng, 1998: Site effect analysis in the Taipei basin: Results from TSMIP network data. Terr. Atmos. Ocean. Sci., 9, 691-704.

Wesson, R. L. and D. M. Perkins, 2001: Spatial correlation of probabilistic earthquake ground motion and loss. Bull. Seismol. Soc. Am., 91, 1498-1515, doi: 10.1785/ 0120000284. [Link] 